\title{
Alternative Justifications for Academic Support III: An Empirical Analysis of the Impact of Academic Support on Perceived Autonomy Support and Humanizing Law Schools
}

Louis N. Schulze Jr.

Florida International University College of Law, Ischulze@fiu.edu

Adam A. Ding

Follow this and additional works at: https://ecollections.law.fiu.edu/faculty_publications

Part of the Law and Psychology Commons, and the Legal Education Commons

\section{Recommended Citation}

Louis N. Schulze Jr. and Adam A. Ding, Alternative Justifications for Academic Support III: An Empirical Analysis of the Impact of Academic Support on Perceived Autonomy Support and Humanizing Law Schools , 38 OHIO N.U. L. REV. 999 (2012).

Available at: https://ecollections.law.fiu.edu/faculty_publications/221 


\section{HEINONLINE}

Citation: 38 Ohio N.U. L. Rev. 999 2011-2012

Provided by:

FIU College of Law

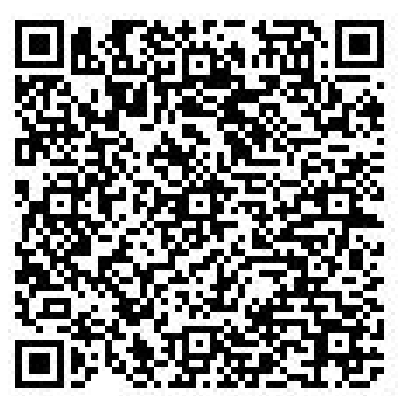

Content downloaded/printed from HeinOnline (http://heinonline.org)

Tue Jun 7 12:38:32 2016

-- Your use of this HeinOnline PDF indicates your acceptance of HeinOnline's Terms and Conditions of the license agreement available at http://heinonline.org/HOL/License

-- The search text of this PDF is generated from uncorrected OCR text.

-- To obtain permission to use this article beyond the scope of your HeinOnline license, please use:

https://www.copyright.com/ccc/basicSearch.do?

\&operation $=$ go\&search Type $=0$

\&lastSearch $=$ simple\&all $=0$ on $\&$ titleOrStdNo $=0094-534 \mathrm{X}$ 


\title{
Alternative Justifications for Academic Support III: An Empirical Analysis of the Impact of Academic Support on Perceived Autonomy Support and Humanizing Law Schools
}

\author{
LOUIS N. SCHULZE, JR. AND A. ADAM DING**
}

\begin{abstract}
This Article details the findings of a two-year empirical study on the impact of a law school academic support program on law students. The hypothesis of the study was that as students' participation in a wellresourced, open-access academic support program increases, students' perception of "autonomy support" and "humanizing" grows as well. The study concludes, based upon statistically significant data, that law school academic support programs impact students in positive ways and therefore are worth the investment. This Article is the third in a series designed to show that law school academic support measures positively impact students' well-being and lead to a more robust educational experience.
\end{abstract}

\section{INTRODUCTION}

Law schools are currently embroiled in a process of making difficult decisions. Thanks to the global recession, budgets are tighter and students are demanding that their tuition be put to good use. Law schools are reexamining costs, and only those endeavors that have a measurable impact upon student well-being, broadly defined, often make the cut. This Article, and the two that preceded it, ${ }^{1}$ argues that law school academic support measures certainly render positive impacts upon students' well-being.

* Professor of Law and Director of Academic Support, New England Law | Boston. My thanks to the many people who assisted in the administration of the survey detailed in this Article and to the students who participated in it. I am indebted to my colleagues who reviewed drafts of this piece, including Professors Elizabeth Bloom, Lawrence Friedman, Jordan Singer, all of New England Law Boston, and Professor Lawrence Krieger of Florida State University College of Law, to New England Law | Boston for its support of this Article, and to my able research assistant, Melaney Hodge.

** Associate Professor of Mathematics, Northeastern University, Ph.D., Comell University.

1. Louis N. Schulze, Jr., Alternative Justifications for Law School Academic Support Programs. Self-Determination Theory, Autonomy Support, and Humanizing the Law School, 5 CHARLESTON L. REV. 269 (2011) [hereinafter Schulze, Jr., Academic Support I]; Louis N. Schulze, Jr., Alternative Justifications for Academic Support II: How "Academic Support Across the Curriculum" Helps Meet the Goals of the Carnegie Report and Best Practices, 40 CAP. U. L. REV. 1 (2012) [hereinafter Schulze, Jr., Academic Support II]. 
Four years ago, Professor Schulze set out on a project to detail the positive impact of law school academic support programs ("ASPs") on law students. The project focused on "alternative" justifications for ASPs, meaning those not directly linking academic support and improved law school grades and bar passage results, per se. Previous studies on those issues existed, ${ }^{2}$ and the debate seemed relatively settled. The project further narrowed the focus by labeling the findings as "justifications" under the theory that, in an economy producing financial cutbacks in both private and public law schools, evidence of some actual impact of these programs would justify their retention or expansion.

What started out as a single paper quickly ballooned into three. The first paper ultimately detailed the methods of academic support that arguably enhance perceived autonomy support among law students and that "humanize" the law school environment." While focusing strictly on descriptive accounts of ASP methodologies around the country, that paper also promised future empirical proof of the claim that such methods provide actual benefits. ${ }^{4}$ The second paper argued how ASPs can help law schools meet the calls for reform of the Educating Lawyers: Preparation for the Profession of Law ("Carnegie Report") ${ }^{5}$ and the Best Practices for Legal Education: A Vision and a Road Map ("Best Practices") ${ }^{6}$ text." Again, that article focused solely on publicizing the methods of ASP and describing the particular portions of the Carnegie Report and Best Practices they help fulfill. ${ }^{8}$

The instant Article makes good on the promise to provide empirical support for the claim that law school ASPs provide actual benefits to students. It features a two-year study determining whether students exposed to academic support perceive higher levels of autonomy support from the law school and whether those same students believe that their law school is more "humane" than otherwise might be the case. In short, in concert with

2. See, e.g., Kevin H. Smith, Program Evaluation: Defining and Measuring "Success" in Academic Support Programs, 2003 L. REV. MICH. ST. U. DET. C.L. 177 (2003) (discussing numerous observations, goals, and objectives to consider in evaluating the success of a law school academic support program); Kristine S. Knaplund \& Richard H. Sander, The Art and Science of Academic Support, $45 \mathrm{~J}$. LEGAL EDUC. 157, 159 (1995) (detailing an exhaustive empirical analysis of the academic effects of academic support at UCLA).

3. See Schulze, Jr., Academic Support I, supra note 1, at 305-20.

4. Id. at 330-31.

5. William M. Sullivan et al., Educating Lawyers: Preparation for the Profession OF LAW (2007) [hereinafter CARNEGIE REPORT]. PRACTICES].

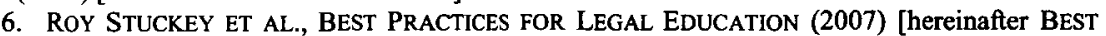

7. See Schulze, Jr., Academic Support II, supra note 1, at 30-64.

8. See id. 
the first two papers, this Article posits that ASPs are "worth it," and that, furthermore, law schools should move to reconceptualize the role of ASPs as a means by which to capitalize on benefits otherwise unlikely to be achieved.

After this Introduction, Part II of this Article describes "selfdetermination theory" and "autonomy support." Because this project has described these concepts before, and because other scholars have done such a fine job doing the same, ${ }^{9}$ this Article concentrates on describing the most recent research and applications of these ideas in law schools. Part III then describes the "law school humanizing" movement. Again, because this is also well-traveled ground, ${ }^{10}$ this Part will focus on the most up-to-date research on-point, especially recent scholarship linking humanization with educational psychology theory. Part IV then details an empirical study of law students' perceptions of ASPs' impact on the degree to which they perceive that their law school provides autonomy support and the degree to which their law school is "humanized." Drawing on the results of the study and the literature on self-determination theory and humanizing, Part V concludes that law school academic support does more than just improve students' grades and bar passage rates: It has the potential to contribute to the holistic improvement of the law school environment and the betterment of our students' health.

\section{SELF-DETERMINATION THEORY AND AUTONOMY SUPPORT}

As previously noted, the literature defining self-determination theory and autonomy support is fairly comprehensive. ${ }^{11}$ This Article will not dwell

9. See generally Corie Rosen, Creating the Optimistic Classroom: What Law Schools Can Learn from Attribution Style Effects, 42 MCGEORGE L. REV. 319, 323-25 (2011); Carol L. Wallinger, Autonomy Support 101: How Using Proven Autonomy Support Techniques Can Increase Law Student Autonomy, Engender Hope, and Improve Outcomes, 48 DUQ. L. REV. 385, 388-91, 395-99 (2010); Lawrence S. Krieger, Human Nature as a New Guiding Philosophy for Legal Education and the Profession, 47 WASHBURN L.J. 247, 248, 262 (2008); Kennon M. Sheldon \& Lawrence S. Krieger, Understanding the Negative Effects of Legal Education on Law Students: A Longitudinal Test of SelfDetermination Theory, 33 PERSONALITY \& SOC. PSYCHOL. BULL. 883, 884 (2007) [hereinafter Understanding the Negative Effects], available at http:/www.immagic.com/eLibrary/ARCHIVES/ GENERAL/SAGEP_UK/S070504S.pdf.

10. See generally Michael Hunter Schwartz, Humanizing Legal Education: An Introduction to a Symposium Whose Time Came, 47 WASHBURN L.J. 235, 239-41 (2008); Barbara Glesner Fines, Fundamental Principles and Challenges of Humanizing Legal Education, 47 WASHBURN L.J. 313-18 (2008); Janet W. Fisher, Putting Students at the Center of Legal Education: How an Emphasis on Outcome Measures in the ABA Standards for Approval of Law Schools Might Transform the Educational Experience of Law Students, 35 S. ILL. U. L.J. 225, 246-47 (2011); Leah M. Christensen, Enhancing Law School Success: A Study of Goal Orientations, Academic Achievement and the Declining Self-Efficacy of Our Law Students, 33 LAW \& PsYCHOL. REV. 57, 81-86 (2009).

11. See supra note 9. 
long on rehashing that ground, but a discussion of the basic concepts will prove helpful. After a brief analysis of those concepts, this section concludes by describing the new research in the field.

\section{A. Defining Autonomy Support and Self-Determination Theory}

Self-determination theory is a branch of psychology that investigates "people's inherent growth tendencies and innate psychological needs." 12 These tendencies and needs in turn provide the basis for self-motivation and personality integration, and self-determination theory thus also focuses on the conditions in human affairs which hinder or support these positive processes. ${ }^{13}$ Positive motivational behaviors are the norm, not the exception, and thus there must be some socio-cultural forces behind negative behaviors such as apathy, alienation, and irresponsibility. ${ }^{14}$ An obvious application of this theory exists in legal education: why do highlymotivated, intelligent students come in to law school eager to learn, yet just months later often seem deflated, defeated, and apathetic?

Self-determination theorists have determined empirically that three inherent needs must be fulfilled in order to lead a person to optimal motivation: competence, relatedness, and autonomy. ${ }^{15}$ These needs "appear to be essential for facilitating optimal functioning of the natural propensities for growth and integration, as well as for constructive social development and personal well-being." 16 The term "competence" refers to "the experience of behavior as effectively enacted." 17 For instance, students perceive competence when they feel that they are capable of meeting the challenges of their learning tasks. ${ }^{18}$ The term "relatedness" means that the learner perceives a sense of belonging in the community in which they are learning. ${ }^{19}$ Put a different way:

In the classroom, relatedness is deeply associated with a student feeling that the teacher genuinely likes, respects,

12. Richard M. Ryan \& Edward L. Deci, Self-Determination Theory and the Facilitation of Intrinsic Motivation, Social Development, and Well-Being, 55 AM. PSYCHOL. 68, 68 (2000), available at http:/www.youblisher.com/files/publications/2/7435/pdf.

13. Id.

14. Id.

15. Id.

16. Id.

17. Christopher P. Niemic \& Richard M. Ryan, Autonomy, Competence, and Relatedness in the Classroom: Applying Self-Determination Theory to Educational Practice, 7 THEORY \& RES. IN EDUC. 133, 135 (2009), available at http://tre.sagepub.com/content $/ 7 / 2 / 133$.

18. Id.

19. Id. at 139 . 
and values him or her. Students who report such relatedness are more likely to exhibit identified and integrated regulation for the arduous tasks involved in learning, whereas those who feel disconnected or rejected by teachers are more likely to move away from internalization and thus respond only to external contingencies and controls. ${ }^{20}$

As it pertains to autonomy, self-determination theory tends to focus on the important difference between intrinsic and extrinsic motivation. ${ }^{21}$ Intrinsic motivation occurs when a person carries out a task because they inherently enjoy doing so. ${ }^{22}$ Extrinsic motivation occurs when some external factors compels performance of the task. ${ }^{23}$ Self-determination theory holds that intrinsic motivation generally leads to more positive behaviors and, in the education context, enhanced learning. ${ }^{24}$ Early experimentation and a watershed meta-analysis confirmed that while tangible rewards (i.e. extrinsic motivation, like a bonus contingent on performance) negatively impact intrinsic motivation, simple positive feedback enhances it. ${ }^{25}$

But, extrinsic motivation can vary in terms of the degree to which it enhances or undermines autonomy. The crucial question is whether a given method of extrinsic motivation is controlling or autonomous; ${ }^{26}$ thus the distinction between extrinsic and intrinsic motivation is not a dichotomy, per se, but instead a sort of continuum. An inherently intrinsic motivation ("I work because I find it fun") is on one end of the continuum; an inherently extrinsic and controlled motivation ("I work because the boss is watching") is at the other end of the spectrum; and an external but internalized motivation ("I work even when the boss is not looking, because

20. Id. at $139-40$.

21. Richard M. Ryan \& Edward L. Deci, Intrinsic and Extrinsic Motivations: Classic Definitions and New Directions, 25 CONTEMP. EDUC. PSYCHOL. 54, 54 (2000), available at http://www.psych.rochester.edu/SDT/documents/2000_RyanDeci_IntExtDefs.pdf.

22. Id. at 55 .

23. Id.

24. Id. Ryan and Deci state:

Intrinsic motivation has emerged as an important phenomena for educators - a natural wellspring of learning and achievement that can be systematically catalyzed or undermined by parent and teacher practices . . . Because intrinsic motivation results in high-quality learning and creativity, it is especially important to detail the factors and forces that engender versus undermine it.

Id. (internal citations omitted).

25. Ryan \& Deci, supra note 21 , at 59 .

26. Id. at 55 . 
doing so will promote my well-being") is somewhere in the middle. ${ }^{27}$ In this regard, extrinsic motivation can positively correlate with increased learning or productivity, but the more autonomous the extrinsic motivation the more likely it will lead to positive learning or working behaviors. In other words, if a teacher uses extrinsic motivation as a tool, it is more likely to produce positive results if that motivation enhances autonomy rather than controls students' choices.

The application of these concepts to legal education is obvious. Although the best case scenario occurs when students are inherently interested in a task involved in their education ("I really digested that case because I am very interested in civil rights law"), many tasks in law school are not inherently interesting. Self-determination theory would tell us that facilitating the internalization of external motivation, by means of promoting autonomy, is crucial in terms of providing students with the necessary motivation to fuel their efforts through less-than-scintillating material. ${ }^{28}$ As an example, a professor might choose to motivate careful reading of cases by randomly cold-calling students in class about the case and then grading students' performance. This would constitute extrinsic motivation ("I read the case closely because I know that I might get called on"), and this method would undermine autonomy because students lack input into selecting the material on which they would be graded (". . . and I resent the fact that my grade is subject to the randomness of cold-calling"). Self-determination theory would urge the professor to motivate careful case reading by allowing students to volunteer for particular cases, but then grade performance by holding students to the same high standards as in the previous method. This would be extrinsic motivation ("I read the case closely because I know I will be graded on it"), but it would serve to enhance students' sense of autonomy (". . . but I did not mind being graded on this material because I got to choose the case and prepare myself thoroughly"). In this way, self-determination theory helps create a positive learning environment without compromising rigor.

\section{B. Self-Determination Theory and Autonomy Support in the Law School}

Any discussion of autonomy support and self-determination theory ("SDT") in law school must begin with the joint works of Kenneth Sheldon and Lawrence Krieger. In Does Legal Education have Undermining Effects

27. See generally id. at 60 (stating that "[ $\mathrm{t}]$ hought of as a continuum, the concept of internalization describes how one's motivation for behavior can range from amotivation or unwillingness, to passive compliance, to active personal commitment.").

28. Id. at 64 . 
on Law Students? Evaluating Changes in Motivation, Values, and WellBeing, ${ }^{29}$ Sheldon and Krieger studied changes in students' "subjective wellbeing" ("SWB") as they entered and progressed through law school. ${ }^{30}$ SWB can be described as:

[P]eople's evaluations of their lives-evaluations that are both affective and cognitive. People experience abundant SWB when they feel many pleasant and few unpleasant emotions, when they are engaged in interesting activities, when they experience many pleasures and few pains, and when they are satisfied with their lives. There are additional features of a valuable life and of mental health, but the field of SWB focuses on people's own evaluations of their lives. ${ }^{31}$

There are also a number of distinct components of SWB: "life satisfaction (global judgments of one's life), satisfaction with important domains (e.g., work satisfaction), positive affect (experiencing many pleasant emotions and moods), and low levels of negative affect (experiencing few unpleasant emotions and moods)." 32 Most importantly, though, positive SWB is associated with positive work (and study) performance, while negative SWB correlates with decreased task performance. ${ }^{33}$ SWB relates to autonomy support in that SDT research shows that "why" a person acts (i.e. if the person is motivated by intrinsic or extrinsic factors and if the person has the autonomy to act on the intrinsic motivation) has "significant consequences for his [or] her satisfaction and performance." ${ }^{34}$ SWB:

A number of factors exist in legal education that decrease students'

Potential negative aspects of legal education include excessive workloads, stress, and competition for academic superiority; institutional emphasis on comparative grading, status-seeking placement practices, and other hierarchical markers of worth; lack

29. Kennon M. Sheldon \& Lawrence S. Krieger, Does Legal Education have Undermining Effects on Law Students? Evaluating Changes in Motivation, Values, and Well-Being, 22 BEHAV. SCI. \& L. 261 (2004) [hereinafter Undermining].

30. Id. at $261,265$.

31. Ed Diener, Subjective Well-Being: The Science of Happiness and a Proposal for a National Index, 55 AM. PsYCH. 34, 34 (2000).

32. Id.

33. See Undermining, supra note 29, at 264.

34. Id. 
of clear and timely feedback; excessive faculty emphasis on analysis and linear thinking, causing loss of connection with feelings, personal morals, values, and sense of self; teaching practices that are isolating or intimidating, and content that is excessively abstract or unrelated to the actual practice of law; and conceptions of law that suppress moral reasoning and creativity. ${ }^{35}$

These factors fundamentally alter law students' SWB by migrating motivation and values from intrinsic to extrinsic. ${ }^{36}$ In other words, if students enter law school motivated by interest or personal convictions but soon are driven instead by coercion, fear, or guilt, their SWB will suffer and, therefore, so will their performance. ${ }^{37}$ Moreover, if students enter law school with intrinsic value content (such as public service, personal growth, or providing top-notch legal services) but instead move towards extrinsic values (such as status or affluence), this too would undermine SWB and, in turn, negatively impact performance. ${ }^{38}$ This migration of motivation and values leads to the negative traits increasingly displayed in the practice of law, such as hyper-competitiveness, greed, and shallowness. ${ }^{39}$

Sheldon and Krieger began their study by confirming empirically that the sample law students, as they entered law school, shared similar SWB as other (non-law) students. ${ }^{40}$ To test whether law school changes students in this regard to a greater extent than other graduate studies, the authors conducted an extensive longitudinal study of students entering an anonymous law school in $2000 .^{41}$ They administered an "attitudes and values" survey to 235 of the 245 entering students in August and then subjected these same students to the survey again in late March. ${ }^{42}$ In so doing, the survey measured them prior to the influence of law school and in the middle of the time in which their SWB would be influenced by their legal education. ${ }^{43}$ The survey measured positive affect, negative affect, life satisfaction, physical health, and depression. ${ }^{44}$ The survey also measured "motivation and values" by asking students, for instance, to write down five law school goals, why they were pursuing those goals, and to describe

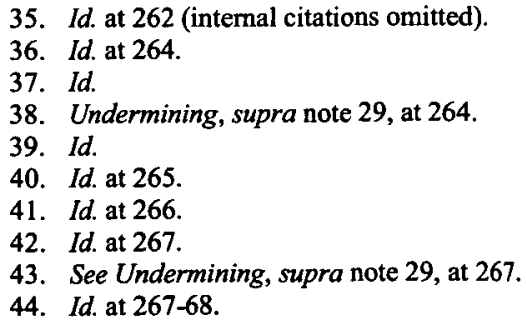


certain aspirations (such as to "have many expensive possessions" or to "help others improve their lives"). ${ }^{45}$

The results showed that students' SWB plummeted over the course of the first year of law school (and later administrations showed that it continued to decline in the second and third years). ${ }^{46}$ While the law students started the year actually with higher positive affect, life satisfaction, and overall SWB than their non-law school peers, ${ }^{47}$ the law school participants experienced large reductions in these categories and large increases in negative affect, depression, and physical symptoms. ${ }^{48}$

As to the motivation and values hypothesis, the results showed that the law students experienced reduced overall self-determination over the course of their first year. ${ }^{49}$ The results further showed a significant "undermining" effect in terms of eroding students' positive motivations, suggesting that law school's lack of autonomy support fosters a usurpation of intrinsic motivation. ${ }^{50}$ As to values, the results showed that students migrated from endorsing intrinsic values to extrinsic ones, suggesting that their legal education even deconstructed students' internal core ideals. ${ }^{51}$ Most importantly, these factors showed a statistical significance in terms of predicting GPA. In other words, avoiding a decrease in SWB and retaining intrinsic motivation and values were positively associated with GPA. ${ }^{52}$ This study was conducted at a second school, and the vast majority of results were replicated. ${ }^{53}$

In 2007, Sheldon and Krieger authored "Understanding the Negative Effects of Legal Education on Law Students: A Longitudinal Test of SelfDetermination Theory." 54 This piece theorized that differences in law schools can reduce the degree of decline in students' SWB. ${ }^{55}$ An important keystone for this hypothesis was that SDT also includes the concepts of "psychological need satisfaction" and the nature of the social context. ${ }^{56}$ In short, the social environment of a learner significantly improves or impedes the development of positive motivation. ${ }^{57}$ Thus, when authorities (i.e. law

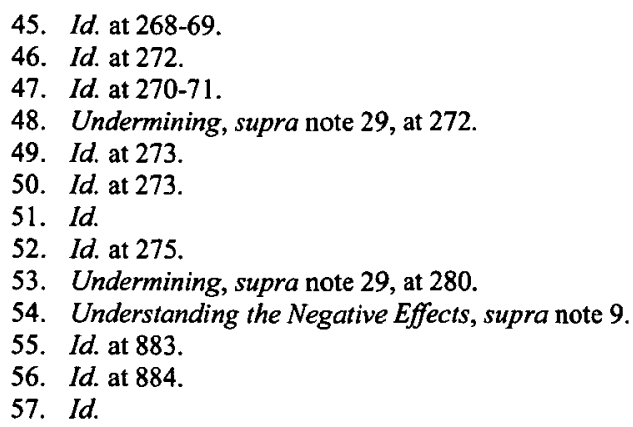


professors or the institution) provide "autonomy support" by recognizing and empowering law students' "initiative and self-directedness," then law students tend to retain intrinsic motivation better even in the face of other factors that might undermine this retention. ${ }^{58}$

In short, autonomy support can act as an "antidote," at least to some extent, to the other deleterious effects of law school. To actualize this antidote, authorities should provide subordinates with:

(a) ... as much choice as possible within the constraints of the task and situation; (b) meaningful rationale provision, in which the authority explains the situation in cases where no choice can be provided; and (c) perspective-taking, in which the authority shows that he or she is aware of, and cares about, the point of view of the subordinate. $^{59}$

By contrast, law schools can exacerbate the already unhealthy effects of legal education by exuding a "controlling" behavior, thus denying students the psychological need of self-agency, undermining intrinsic motivation, and forestalling internalization. ${ }^{60}$

Given their 2004 findings that law school undermines students' SWB, Sheldon and Krieger sought in their 2007 study to measure whether the provision of autonomy support might mitigate that undermining effect. ${ }^{61}$ As such, it was important to study two law schools, one with a focus on providing autonomy support and the other lacking that focus. ${ }^{62}$ The two law schools were similar in that they admitted students of the same high caliber, but they differed substantially in terms of "educational and pedagogical philosophies."63 In terms of faculty hiring, law school one ("LS1") focused heavily on candidates' scholarly productivity, while law school two ("LS2") concentrated more on law practice and public service experience and demonstrated teaching ability. ${ }^{64}$ LS2 also differed from LS1 in that it "regularly provide[d] teaching skills seminars for its faculty, ha[d] many more faculty members devoted to practical skills training, and combine[d] skills and theory instructors into one integrated faculty." provided more skills courses to develop students' practice abilities, "and

58. $I d$.

59. Understanding the Negative Effects, supra note 9, at 884 .

60. Id. at 884 .

61. Id. at 886 .

62. Id.

63. Id.

64. Understanding the Negative Effects, supra note 9, at 886.

65. Id. 
ha[d] a cocurricular requirement for students that further[ed] their professional development and help[ed] with stress and mental health concerns." ${ }^{.66}$ The authors concluded from these facts that the stronger orientation toward student interests and priorities at LS2 suggests the likelihood of a greater degree of autonomy support. ${ }^{67}$

Like their 2004 study, Sheldon and Krieger surveyed incoming firstyear students at both schools early in their law studies. ${ }^{68}$ They then tested these same students at the end of their first year and during students' third year, as they neared graduation. ${ }^{69}$ In this study, the authors used standardized survey instruments to measure students' grades, SWB (in a way similar to the 2004 study), need satisfaction (including autonomy, competence, and relatedness), self-determined career motivation, and perceived autonomy support ${ }^{70}$ (using the same instrument used in the instant study). ${ }^{71}$

The results of the surveys confirmed the authors' hypotheses. ${ }^{72}$ As the students at the two schools began their first year, LS1 and LS2 had relatively indistinguishable variables. ${ }^{73}$ After that first year, though, LS2 (the more student-focused school) showed higher levels of perceived autonomy support. ${ }^{74}$ As predicted, LS2's Year Three SWB measure was significantly higher, as was its competence-need satisfaction. ${ }^{75}$ More strikingly, LS2 students had achieved a higher final GPA compared to students at LS1, and they scored higher on the Multistate Bar Examination than students at LS1 (even though LS1 students had superior incoming LSAT and GPA, and attended a higher-ranked law school) ${ }^{76}$ While noting that further conclusive research is needed, the authors nevertheless concluded that "it appears that the more autonomy-supportive teaching at LS2 may ultimately have produced better learning mastery among LS2 students ....,"77

Thus, Sheldon and Krieger's studies suggest that: (a) legal education has an undermining effect on students' SWB; and (2) a law school's educational and pedagogical choices can mitigate these effects by

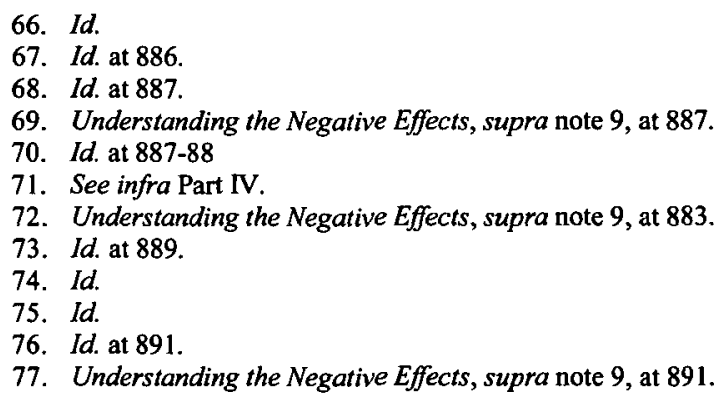


supporting students' autonomy in learning. ${ }^{78}$ With this foundation, the next section explores the latest research on these subjects.

\section{The Latest Research on Autonomy Support and Self-Determination Theory}

As noted previously, scholars have extensively discussed the works of Sheldon and Krieger, and thus the brief treatment of them here is due to an aversion to repetition and not a failure to recognize the studies' importance. A review of more recent work reveals a rich discourse on law school autonomy support, self-determination theory, and positive psychology. Recent articles have focused on implementing autonomy support in the classroom and on the impact of SDT on professional character formation.

As for implementing autonomy support in the classroom, recent scholarship tells us that law professors can enhance autonomy support in the way they respond to student questions. ${ }^{79}$ There are a number of scenarios in which law professors' responses to students can either be autonomysupportive or detrimental to students' autonomy. ${ }^{80}$ The key to the autonomy-supportive responses boils down to whether the professorial response contributes to students' internalization of a lawyerly value or undermines it. ${ }^{81}$ Internalization is the "“process through which an individual transforms a formally externally prescribed regulation or value into an internally endorsed one. ${ }^{\prime, 82}$ Extrinsic motivation, which is generally the method law professors most regularly employ, varies in terms of whether it is controlling (highly or moderately) or autonomy-supportive (highly or moderately). ${ }^{83}$ The degree to which the extrinsic motivation is controlling or autonomy-supportive, in turn, impacts the extent to which the regulation or value is internalized. ${ }^{84}$

The four different types of regulation, in increasing order of autonomous behavior, are: external, introjected, identified, and integrated. ${ }^{85}$ While law professors ordinarily cannot externally provide integrated extrinsic motivation, providing identified regulation makes it far more likely that a student will internalize a given lawyerly value. ${ }^{86}$ For this reason,

78. Id. at 885

79. See Wallinger, supra note 9 , at $399-401$.

80. Id. at $400-01$.

81. Id. at 388 .

82. Id. at 388-89 (quoting John Marshall ReEve, Understanding Motivation AND EMOTION 164 (5th ed. 2008))

83. $I d$. at 389.

84. Wallinger, supra note 9 , at 389.

85. Id. at 389 .

86. Id. 
answering students' questions in a way that provides the three factors of autonomy support-choice, rationale provision, and perspectivetaking - enhances the likelihood of internalization. ${ }^{87}$

Let us take, for example, a Contracts class in which students one day ask the age old question: "what study guides do you recommend?" A highly controlling response would assert that all students must learn the course materials only from one source: a particular treatise that has been popular since well before the professor's law school days. The professor further indicates that any other study guides are a complete waste of time, and failure to use the recommended guide will undoubtedly result in negative performance. The professor fails to indicate any rationale for this belief, but believes that her strongly-worded admonition should be sufficient proof of the superiority of the particular treatise. Whether the professor is correct on the merits or not, the class as a whole likely will not learn optimally from this recommendation because the professor employed a highly controlling method of extrinsic motivation; students who were previously doing the "right thing" (i.e. conscientiously seeking out more work to help their studies) now are deflated.

By contrast, let us assume that students ask the same question in another section of Contracts. Let us further assume that this Contracts professor believes equally strongly in the superiority of the same treatise. Instead of using a highly controlling extrinsic motivation, the professor incorporates the three aspects of autonomy support (choice, rationale provision, and perspective-taking) in her answer. She responds that students should feel free to experiment with whatever Contracts supplements might work best with their own learning styles, but she feels strongly that the above treatise is students' best hope. She spends a few seconds explaining that she often turns to this text herself while preparing for class, that many of her exam hypotheticals draw indirectly from this text, and the treatise is organized in the same way as the professor's course. Finally, the professor states that she would appreciate any students letting her know if they find the recommended treatise helpful and further requests that students submit any suggestions for other books. In this response, the professor has used an autonomy enhancing response style and likely has primed her students for the successful use of the recommended supplement. By providing a rationale for the constraint on students' choice, she has likely gone far in motivating students towards integrating her belief as their own. 
Having discussed autonomy support, self-determination theory, and recent scholarship, this Article turns now to a discussion of what it means to "humanize" a law school.

\section{THE MOVEMENT TO HUMANIZE LAW SCHOOLS}

This section discusses the efforts of faculty, administrators, and lawyers to "humanize" the law school experience and, more broadly, the practice of law. Previous efforts have been made to chronicle the history of this movement, ${ }^{88}$ so this section will instead focus on describing the movement and detailing recent scholarship in the field.

\section{A. A Brief Description of the Movement and its Goals}

The Humanizing Law School website at the Florida State University College of Law stands as a sort of epicenter of the humanizing movement. ${ }^{89}$ That website defines humanizing as follows:

Humanizing legal education is an initiative shared by legal educators seeking to maximize the overall health, well-being and career satisfaction of law students and lawyers. We find cause for concern in our observations of law students and in the research on, and reports of, problems in the legal profession-including dissatisfaction, depression, excessive work, substance abuse and eroding professionalism. We are interested in the ways legal education is conducted, the impact those choices may have on the attitudes, values, health and well-being of law students, and the possible relationship between each of those matters and the problems experienced by our graduates in the profession. Through scholarship, Web-based discussion, empirical research and conferences, we hope to inform the development of innovative teaching methods when appropriate. ${ }^{90}$

Scholars in the field of psychology have attempted to define the movement, focusing on its impact on human nature. For instance, Professor

88. See Bnuce J. Winick, Foreword: What Does Balance in Legal Education Mean?, 60 J. LEGAL EDUC. 107, 107 (2010). Interestingly, when creating a section within the Association of American Law Schools on humanizing law school, the section organizers deliberately chose not to use the term "humanizing." Id. at 108 . They felt that the phrase "could be easily misunderstood, might be off-putting to some, and also might be too narrow in light of the many potential reforms that could improve legal education." Id.

89. See Humanizing Law School, THE FLA. ST. U., http://www.law.fsu.edu/academic_programs/ humanizing lawschool/humanizing lawschool.html (last visited July 27, 2012).

90. Id. 
Larry Krieger, after analyzing recent research on core human qualities, offered the following thoughts:

We may ... define a "humanizing" social environment or social context as one that promotes these experiences of an optimally functioning person. Such an activity or context would incorporate an understanding of human nature and would therefore maximize meaning, positive motivation, well-being, and performance. More specifically, it would provide consistent autonomy support and encourage intrinsic values and motivations, resulting in (1) needed experiences of autonomy, authenticity, competence, and relatedness to others; and (2) experiences of personal growth and increasing integrity, through the integrated expansion of authenticity, conscience, morality, and social awareness. ${ }^{91}$

Moreover, attempts have been made to describe the opposite of humanization, i.e. a dehumanizing law school environment. Professor Susan Grover, for instance, notes that the common maladies of lawyers, "work addiction, substance addiction, depression, general dissatisfaction, and ill health," begin in law school. ${ }^{92}$ She suggests that law students tend to abandon core, healthy activities and aspects of their personalities during law school, presuming that these changes are temporary and easily regained upon successful completion of law school. ${ }^{93}$ Instead, these substantial changes cut to the very core of the student's psyche, and "[w]hen students reject vital aspects of themselves in the name of becoming lawyers, they act to the detriment of their own psychological integration." 94 This, in turn, leads to a more permanent psychological harm that remains with students into their careers. ${ }^{95}$

All of this discourse led to the inclusion of humanizing principles in two recent momentous reports on the status of legal education: the Carnegie Report ${ }^{96}$ and Best Practices. ${ }^{97}$ It might be fair to say that Best Practices addresses humanizing concepts a bit more explicitly than the Carnegie Report. For instance, in a chapter addressing "Best Practices for Delivering Instruction, Generally," the authors devote a subchapter to creating and

91. Understanding the Negative Effects, supra note 9, at 260-61.

92. Susan Grover, Personal Integration and Outsider Status as Factors in Law Student WellBeing, 47 WASHBURN L.J. 419, 421 (2008).

93. Id. at 421-23.

94. Id. at 422 .

95. See Id.

96. CARNEGIE REPORT, supra note 5.

97. BEST PRACTICES, supra note 6. 
maintaining "effective and healthy teaching and learning environments." This subchapter includes advice to "do no harm to students," "support student autonomy," "foster a supportive environment," "make students feel welcome and included," and "help students improve their self-directed learning skills." ${ }^{\circ 9}$ All these terms stem directly from the humanizing movement.

For instance, the term "do no harm to students" hails from Professor Barbara Glesner Fines' article, "Fundamental Principles and Challenges of Humanizing Legal Education." 100 In that piece, Professor Glesner Fines notes three "elements" of humanizing: (1) "do no harm"; (2) teach students, not subjects; and (3) "peace and justice.", "Doing no harm" generally suggests that "law schools need to identify negative stressors in the law school environment, reduce or eliminate those as much as possible, and help the students to manage those that cannot be eliminated."102 This advice led the Best Practices authors to question law schools' overly competitive nature, the relative lack of feedback, the misuse of the Socratic dialogue and case method, and other methods that might prevent students from feeling free from in-class humiliation. ${ }^{103}$ Moreover, the admonition to support student autonomy focuses on SDT, the studies of Sheldon and Krieger, and the conclusion that autonomy supported law students find more success on the bar exam. ${ }^{104}$

In suggesting that law schools "foster mutual respect among students and teachers," Best Practices suggests that professors learn students' names, learn about students' experiences and use them in class, and define and model respect in the classroom. ${ }^{105}$ As to helping "students improve their self-directed learning skills," Best Practices draws on research by Professor Michael Hunter Schwartz, ${ }^{106}$ also an author in the humanizing field. ${ }^{107}$ Selfdirected learning involves

a cyclical process in which self-directed learners appropriately classify the demands of a learning task, plan strategies for learning what needs to be learned, implement those strategies while self-

\footnotetext{
98. Id. at 110.

99. See generally id. at 111-30.

100. See Fines, supra note 10, at 313-18.

101. Id. at $313,318,322$.

102. Id. at 313-14.

103. BEST PRACTICES, supra note 6, at 111-12.

104. Id. at 113-14.

105. Id. at 114-15.

106. Id. at 127.

107. Schwartz, supra note 10.
} 
monitoring the effectiveness and efficiency of the chosen strategies, and reflect on the success of the process afterwards .... ${ }^{108}$

This method of strategizing and self-critique typifies the best lawyers, as well, in that those who excel in practice are constantly assessing the effectiveness of such skills as cross-examination, transactional abilities, or client counseling. This theme applies in academic support as well: proper academic support focuses not on tutoring, which many in the field agree displaces the autonomy of learning from student to tutor, but instead upon instilling self-directed learning skills. Clearly, Best Practices has much to say about humanizing which, in turn, has much to do with the goals of academic support.

The Carnegie Report makes fewer overt references to humanizing principles, but a closer analysis reveals a significant correlation. An important feature of humanizing is to maintain the connection, during law school, between students' learning and their purpose in lawyering. Traditionally, legal education often acted to sever students' connection to their original reason for pursuing a law degree. ${ }^{109}$ The task of converting students to a more logical, objective analytical mindset often divorced them from the more subjective topic of purpose. ${ }^{110}$ Humanizing seeks to reconnect legal education to the process of facilitating students' purpose, while at the same time maintaining the rigorous and objective analysis of legal problems. ${ }^{111}$

Professor Glesner Fines echoes this sentiment in the third item in her definition of humanizing: "The call to humanize legal education is part of a much larger call to humanize the profession by recapturing the essence of professional values-peacemaking, problem solving, and justice work." 12 She reflects that a challenge to this ideal exists in the fact that legal education often leaves students with the not-so-subtle impression that serving individual clients, especially those of limited incomes, is secondrate when compared to work in the private sector, representing institutional clients. ${ }^{113}$ Humanizing seeks to even the playing field, giving the

108. Best PRACTICES, supra note 6, at 127.

109. See generally CARNEGIE REPORT, supra note 5, at 133.

110. "[I]n the minds of many faculty, ethical and social values are subjective and indeterminate and, for that reason, can potentially even conflict with the all-important values of the academy-values that underlie the cognitive apprenticeship: rigor, skepticism, intellectual distance, and objectivity." $I d$. at 133.

111. Humanizing acts "to interrupt the stultifying, personally narrowing effects of ignoring morality, conscience, and caring, or casting them as 'counter-productive relics from [students'] pre-law lives."' Krieger, supra note 9, at 285.

112. Fines, supra note 10 , at 322.

113. Id. 
impression to students that BigLaw work is one valid choice, as is working in a public interest context. Moreover, humanizing seeks to establish in all students, including those headed to large law firms, that a focus on problem solving and a commitment to justice should pervade their practice of law regardless of its setting.

Similar themes appear in the Carnegie Report. One of the three "apprenticeships" of law school, the authors posit, focuses on the importance of "professional identity and purpose" in educating future attorneys. ${ }^{114}$ The authors assert that essential characteristics of a professional lawyer includes "dedication to justice and the public good," an idea that closely parallels those of the humanizing movement. ${ }^{115}$ Furthermore, the authors discuss the same hierarchy of practice areas as proponents of humanizing: "“peacemaking, problem-solving lawyers are the legal profession's equivalent of doctors who practice preventative medicine. Their efforts are generally overshadowed by the heroics of surgeons and litigators." "116 Meanwhile, law school embeds this hierarchy implicitly:

The focus of law school on the juridical-process-as-conflict resonates with the dominant images of the lawyer in popular circulation ... . However atypical the tense courtroom drama may be in the careers of most lawyers, the important dimensions of lawyer as counselor and court officer are simply less visible unless they are regularly analyzed, modeled, and practiced .... ${ }^{117}$

Thus, the Carnegie Report authors recognize, as do humanizers, that the gladiatorial image of lawyers, subtly reinforced by means of the law school curriculum (i.e. the case book method, showing zero-sum-game conflict resolution) creates a reality in which problem-solving and peacemaking are largely ignored.

Therefore, in suggesting remedies for the negative aspects of law school, it is no surprise that the Carnegie Report suggests methods very much in-tune with those of the humanizing movement. For instance, the Carnegie Report highlighted a course taught by Dean Daisy Floyd of Mercer University School of Law, called "Advanced Legal Ethics." 18 Students in that course "read and discuss[ed] essays on the history of legal education, research on

114. CARNEGIE REPORT, supra note 5, at 126.

115. Id.

116. Id. at 127 (quoting MARY ANN GLENDON, A NATION UNDER LAWYERS: HOW THE CRISIS IN THE LEGAL PROFESSION IS TRANSFORMING AMERICAN SOCIETY 107 (reprint ed. 1996)).

117. Id.

118. Id. at 155 . 
legal education, legal practice, and professions more broadly," and lawyers and other professionals participated as guest speakers. ${ }^{119}$ Subjects discussed included: "developing the inner life"; "developing connections with colleagues and clients"; "the role and nature of lawyers in society"; "the legal culture, including adversarialism, competition, and the emphasis on winning"; "the practice of law as a calling"; "the law and lawyers as healers"; "finding meaning and satisfaction as a lawyer"; and "the relationship between psychological wholeness and professional competence." 120 Dean Floyd reported that the course helped students reclaim a sense of purpose in their future careers, a sense that law school had devalued for them. ${ }^{121}$ Courses like these, the Carnegie Report suggests, allow students not only to attend to the "cognitive apprenticeship" of law school but also to balance intellectual rigor with professional purpose, SWB, and a pursuit of social justice. $^{122}$

By analyzing these texts through the lens of the concepts of humanizing, we can conclude that the voice of the humanizing movement is broader than merely a few isolated reformers. Seeing the parallels between the definitions of the humanizing movement and the themes of Best Practices and the Carnegie Report, it is clear that many legal educators are on board with the project of training lawyers holistically while simultaneously maintaining the intellectual rigor of traditional legal education. It is important now to understand the latest research in the field.

\section{B. The Latest Research on Humanizing Legal Education}

An important recent theme in the literature on humanizing the law school experience is that of positive psychology. ${ }^{123}$ Studies show that law students suffer from drastically elevated levels of stress, as compared to other graduate students, and that lawyers are the professional group most susceptible to alcoholism, depression, and drug problems. ${ }^{124}$ A growing number of legal educators seek to reverse this trend by identifying the aspects of law school that so debilitate its constituents and by eliminating or

119. Id. at 156 .

120. Daisy Hurst Floyd, The Development of Professional Identity in Law Students (June 2002) (unpublished manuscript), available at http://www.law.fsu.edu/academic_programs/humanizing _ lawschool/images/daisy.pdf.

121. CARNEGIE REPORT, supra note 5, at 156 .

122. See id. at 155 .

123. See Rosen, supra note 9, at 319; Todd David Peterson \& Elizabeth Waters Peterson, Stemming the Tide of Law Student Depression: What Law Schools Need to Learn from the Science of Positive Psychology, 9 YAle J. HeAlTH POL'Y, L. \& ETHICS 357, 358 (2009).

124. Richard Sheehy \& John J. Horan, Effects of Stress Inoculation Training for Ist-Year Law Students, 11 INT'L J. STRESS MGMT. 41, 52 (2004). 
mitigating those aspects. As a result, many scholars now research the potential impact of positive psychology upon the law school environment.

Generally speaking, positive psychology studies positive emotions, positive character traits, and enabling institutions. ${ }^{125}$ Three subjects define the field of positive psychology: "(1) positive individual characteristics (strengths and virtues), (2) positive subjective experience (happiness, pleasure, and meaning), and (3) positive institutions and communities."126 While clinical psychology focuses on the disease model of the study of mental well-being, and is thus reactive, positive psychology attempts to put forth a proactive methodology to prevent negative psychological experience. ${ }^{127}$ In law schools, implementing some of the knowledge from positive psychology would represent a drastic shift in how law schools contend with mental wellness; while presently law schools react to student psychological suffering by means of $a d$ hoc counseling services, those who champion positive psychology seek to implement reform in law schools for the purpose of avoiding the psychologically debilitating stressors in the first place. ${ }^{128}$ Interestingly, this reform often does not seek the wholesale dismantling of traditional law school methods, like the Socratic method, rigorous grading, and the like. ${ }^{129}$ Instead, positive psychology-based reform often seeks to implement changes on the students' end to fortify them for success and wellness in law school.

For instance, a recent study conducted by Peterson and Peterson applied the "strengths theory" of positive psychology in a law school context. ${ }^{130}$ Strengths theory is the concept "that people can benefit from a focus on those qualities and actions that come naturally to them, that they enjoy doing, and that they do well."131 Researchers in the field developed a list of six virtues that transcend culture and enable thriving, and then further divided those core virtues into a list of twenty-four character strengths. ${ }^{132}$ These strengths included concepts such as "love of learning," "persistence," "social intelligence," "leadership," "prudence," and "hope.," "Vh3 The researchers then created an inventory assessment tool, called the "Values in

125. Peterson \& Peterson, supra note 123 , at 362.

126. Id. at 387.

127. Id. at 362 .

128. Id.

129. Id. at 378, 384; but see Andrea P. Goldin et al., From Ancient Greece to Modern Education: Universality and Lack of Generalization of the Socratic Dialogue, 5 MIND, BRAIN, AND EDUC. 180, 180 81 (December 2011) (purporting to refute the effectiveness of the Socratic method using empirical methods).

130. Peterson \& Peterson, supra note 123 , at 408

131. Id. at 406 .

132. Id. at $387-88$.

133. Id. at 388 . 
Action Inventory of Strengths,"134 and showed that focus on one's core strengths correlates with an increased likelihood of academic success and SWB. ${ }^{135}$ Lest one think, though, that these categories are some "touchyfeely" endeavor to get people more "in touch with their emotions" and other fuzzy goals, one should realize that these methods were employed successfully at the United States Military Academy. ${ }^{136}$ Multiple studies, focusing on workers, high school students, and post-secondary students, all confirm that focusing one's endeavors by leveraging "signature strengths" increase performance, predict improved task performance, and lead to enhanced subjective self-efficacy. ${ }^{137}$

This theory was applied in a law school setting in the Peterson and Peterson study. There, the researchers recruited George Washington University law students of all years to participate in a survey that included a questionnaire administered in late March, while classes were ongoing. ${ }^{138}$ The questionnaire included seventy-eight questions and ultimately was administered in an online format to 140 students (64 men, 76 women). ${ }^{139}$ After gathering demographic information such as gender, law school year, and GPA, the survey tested for life satisfaction, stress, depression, and character strengths. ${ }^{140}$ The survey used self-reporting instruments commonly applied in those four respective fields, proven in the past to be reliable and valid. ${ }^{141}$ In particular, Peterson and Peterson used the Values in Action Inventory of Strengths to determine each respondent's character strengths. ${ }^{142}$ They then measured the aggregate life satisfaction, stress, depression, and character strengths of the aggregate group and sought to determine any correlations between those four data points. ${ }^{143}$

Unsurprisingly, there was a statistically demonstrable correlation between stress and depression. ${ }^{144}$ As other studies of law students had shown, these students demonstrated levels of stress and depression far above that of the average person. ${ }^{145}$ While young adults in general measure at a rate of eleven percent for clinical levels of depression, the Peterson and Peterson study of law students found that fifty-three percent of its subjects

\footnotetext{
134. Id. at 389.

135. Peterson \& Peterson, supra note 123 , at $389-90$.

136. Id. at 390 .

137. Id. at $407-08$.

138. Id. at $409-11$.

139. Id. at 409.

140. Peterson \& Peterson, supra note 123 , at 409.

141. Id.

142. Id. at $409-11$.

143. Id.

144. Id. at 411-16.

145. Peterson \& Peterson, supra note 123 , at $412-13$.
} 
demonstrated that level. ${ }^{146}$ As the authors relate, this level of depression results in a weakened ability to process and store information, to disengagement from tasks, and to alcohol and drug abuse. ${ }^{147}$

The study also confirmed the researchers' hypothesis that those students who more frequently used their top strengths more often day-to-day would be more likely to report higher life satisfaction and lower levels of stress and depression. ${ }^{148}$ While the authors did note correlative and not causative results, and further suggested that happy students might simply use their life strengths naturally, they concluded (by reviewing the correlation with other studies in the general population) that law schools should pursue the implementation of "strength theory" as a means to buffer students from the ill effects of stress and depression. ${ }^{149}$

Having discussed the concepts of self-determination theory, autonomy support, and humanizing, the next step is to determine whether ASPs truly impact these concepts. Thus, Part IV details a survey of students conducted to determine how law school academic support impacts students' perceptions of the degree to which law school supports or undermines these goals.

\section{EMPIRICAL ANALYSIS: ACADEMIC SUPPORT, PERCEIVED AUTONOMY SUPPORT, AND HUMANIZING}

This Part details a study of students' perceptions of autonomy support and humanizing, comparing those students who participated regularly in academic support endeavors with those who did not. As the analysis will show, generally speaking, as participation in the ASP increased, so did students' perception of autonomy support and humanizing.

\section{A. Methodology}

The following section discusses the methods used in this study. It details the hypothesis to be tested, the survey instrument, the procedures employed in the administration of the survey, and the nature of the questions asked.

\section{The Hypothesis Sought to be Tested.}

The working hypothesis of the study was that the availability and use of academic support resources would increase a student's perceived autonomy

146. Id.

147. Id. at 413-14.

148. Id. at 411-14.

149. Id. 
support and perception of humanization of the law school environment. The study sought to test this hypothesis by comparing students who selfreported high levels of use of the academic support resources against students who self-reported lower levels of use of those resources. Aggregate scores showing stronger levels of perceived autonomy support and humanizing among heavy users of academic support would evidence a correlation between academic support and these principles. ${ }^{150}$ Thus, this bivariate analysis sought to test the correlation between: (a) academic support and autonomy support; and (b) academic support and perception of humanizing.

\section{The Survey Instrument and the Procedures of its Administration.}

The study was comprised of a survey instrument designed to determine each individual respondent's perception of the degree to which the law school fosters autonomy support and promotes a humanized environment. Survey administrators distributed this instrument twice at New England Law | Boston: once in the fall of 2009 (T1) and once in the fall of 2010 (T2). In each administration of the survey, responses were solicited from all full-time first and second-year students. ${ }^{151}$ To accomplish this, the survey was distributed in each of the law school's three first-year day sections and in each of the law school's three second-year Evidence classes. ${ }^{152}$

By giving students about ten minutes to complete the survey before the beginning of classes, the vast majority of targeted students completed

150. See PAS-Leaming Climate: The Learning Climate Questionnaire, SELF-DETERMINATION THEORY, http://www.selfdeterminationtheory.org/questionnaires/10-questionnaires/82 (last visited July $26,2012$ ) [hereinafter Learning Climate Questionnaire] (stating that "[ $\mathrm{h}]$ igher average scores represent a higher level of perceived autonomy support.").

151. This study exempted evening students due to the possibility that part-time students' perceptions of the law school, due to their minimal time within the law school per week, could differ qualitatively from full-time students. Mixing this data would undermine the validity of the results.

Furthermore, the study exempted third-year students from participation for several reasons. First, unlike first and second-year students, third-year students at New England have no mandatory classes in common. As such, administering the instrument would have presented significant logistical problems. Second, third-year law students at New England tend to spend a significant portion of their weekly schedule outside the law school. As such, their perception of the law school's atmosphere could differ substantially from that of first and second-year students. Finally, third-year students at New England do not have access to class-wide academic support services. While they do have access to one-on-one academic counseling with Academic Excellence professors, there is no "classroom component" for thirdyears. By contrast, all first-year students may attend weekly Academic Excellence classes (available to each section), and second-year students on "Academic Concern" may enroll in the two-credit "Legal Analysis" class. These differences create a qualitative difference in terms of the current academic support experiences of third-year students.

152. Because Evidence is a required course in students' third semester, this method distributed the survey to all second-year students. 
surveys. Out of the 289 students enrolled as full-time, first-year students in 2009,236 completed a survey. Out of the 233 students enrolled as fulltime, second-year students in 2009,171 completed a survey. Out of the 295 students enrolled as full-time, first-year students in 2010, 252 completed a survey. Out of the 264 students enrolled as full-time, second-year students in 2010,188 completed a survey. This represents a response rate of $81.66 \%, 73.39 \%, 85.42$, and $71.21 \%$ respectively. Social science research holds that a response rate of about sixty percent is considered sufficient to draw generalized conclusions from human subject survey data. ${ }^{153}$

The survey instrument, together with verbal instructions, informed students that their participation in the survey was strictly voluntary. ${ }^{154}$ The administration of each survey also included anonymous procedures by which students could "opt out" of the survey in a way that would not publicly disclose the student's lack of participation. ${ }^{155}$ Also, both the written and verbal instructions expressly noted that the individual results of the survey were anonymous; students were instructed not to write their names or other identifying information on the survey instrument. ${ }^{156}$ The instructions also informed student subjects that neither the law school administration nor individual instructors would have knowledge of individual survey results. ${ }^{157}$ Survey administrators also informed subjects that the survey complied procedures established by the U.S. Department of Health and Human Services for the protection of human research subjects ${ }^{158}$ and with the approval of the law school's Institutional Review Board. ${ }^{159}$

153. EARl R. BABbie, THE PRACTICE OF SOCIAL RESEARCH 256 (2001) (stating that for a traditional, non-web-based survey, a response rate of fifty percent is adequate; sixty percent is good; seventy percent is very good).

154. 2009 \& 2010 Survey Instruments (on file with the author).

155. Id. Specifically, students were told to hand in the survey at the completion of the administration, but were told to leave the form blank. This ensured that other students would have no knowledge of a student's non-participation.

156. Id.

157. Id.

158. Id.

159. A side note is warranted with respect to this topic. Research requires approval of an "Institutional Review Board" whenever the study uses "human subjects" in any manner. This requirement applies to extremely invasive research, such as that in the medical field, potentially psychologically harmful research, and even mundane, wholly benign research such as the instant study.

This requirement posed a significant obstacle to the completion of this research in that, despite federal legislation and regulations governing the topic, many schools have adopted different approaches to this issue. This was relevant to this research because the initial research plan attempted to measure the impact of ASPs, or the lack of them, at about a dozen anonymous law schools. This led to several problems.

First, many law school administrators were under the mistaken impression that a research plan must receive IRB approval at every school where research will occur. This is incorrect: if a researcher's home IRB approves the study, that approval travels with the research. 
Finally, prior to participating, student subjects received the following description of the purpose of the research:

I have to explain to you the purpose of the survey and how it will be used. This survey studies the impact of academic support on law students, specifically whether academic support enhances students' perception of a psychological theory called 'autonomy support and another theory called 'humanizing the law school.' Aggregate statistics will be compiled for publication in a law review article authored [in part] by Professor Schulze. ${ }^{160}$

These procedures helped ensure two things. First, they ensured that students' participation in the study occurred with their informed consent. By informing students of the nature of the research and its purpose, together with a mechanism of opting out, participating students had prior knowledge of the potential impact of their decision to complete a survey. Second, the procedures also helped to ensure honest answers. By informing students that no member of the faculty would know individual student responses, including the director of the academic support program, students could feel free to express their true feelings, even if those feelings included negative criticism of the program. These procedures are typical in social science quantitative studies, and they enhance the scientific nature and statistical significance of the study.

\section{The Nature of the Questions in the Survey}

The survey questions, numbering twenty-five in total, fell into three categories. The first category included questions pertaining to students' participation in the law school's academic support resources. Questions one

Second, several schools seemed to use the IRB process as a means by which to discourage the instant study. There were two types of law schools sought for study: those with ASPs and those without. The research plan sought to compare the perceived autonomy support and humanizing of law schools with ASPs against those without one. The hypothesis was that law schools without ASPs would demonstrate lower levels of these concepts.

Several law schools without ASPs imposed overly strenuous IRB requirements upon the instant research, thus effectively scuttling the project. By contrast, all schools with ASPs that were approached, i.e. those who would likely have performed strongly in terms of autonomy support and humanizing, either did not require local IRB approval or quickly approved the research plan under expedited procedures. Additionally, several non-ASP law schools (but nonetheless boasting academic support resources on their websites), expressly rejected the research plan without local IRB review and despite the approval by the researcher's law school's IRB approval. Due to this situation, the research plan ultimately focused solely on the researcher's own law school.

Law schools need better information regarding the IRB process and the appropriateness of empirical research using human subjects. Further scholarship in this area would be warranted as a means by which to educate law schools on IRBs.

160. Survey Instructions Form (on file with the author). 
to three were within this category, and the response types varied from "dichotomous responses" ${ }^{161}$ to "ordinal-polytomous"162 responses. $^{163}$ As this Article discusses, these questions allowed the researchers to sort students into those who used the academic support services extensively from those who used them moderately and those who used the resources infrequently, thus permitting testing of the study's hypothesis.

The second category related to autonomy support. The survey questions stem directly from those created by the Department of Psychology at the University of Rochester, studying autonomy support by surveying students using the scientifically validated ${ }^{164}$ "Learning Climate Questionnaire [("LCQ")]."165 The instant study modified these questions for use in a law school setting and to test a general learning climate and not an individual instructor; the LCQ specifically details this procedure. ${ }^{166}$ Furthermore, these are the same questions used by Sheldon and Krieger in studying autonomy support. ${ }^{167}$ As such, these questions are wellestablished for the purpose of discerning differences in autonomy support. Questions ten to twenty-four are within this category, and each question employed a five-point Likert Scale response type. ${ }^{168}$ Examples include questions such as "Agree or Disagree: My law school as a whole (including the Academic Excellence Program) provides me with choices and options that allow me to govern or regulate my own education." 169

The third category pertains to law school humanization. Although there was no previous survey instrument in this context available for replication, this study patterned these questions around those developed by the University of Rochester researchers, as later used by Sheldon and Krieger. As a basis for the substance of the questions, this study used factors articulated in the literature of humanizing such as identifying and mitigating negative stressors, providing feedback, and problem solving and justice. Questions four to nine are within this category, and each question employed

161. In this type of response, respondents choose between two mutually exclusive choices, such as "I attended the 1L Mock Exam" versus "I did not attend the 1L Mock Exam."

162. In this response type, the respondent has more than two ordered options. For instance: (a) I have attended all or nearly all AEP classes (9-10 classes); (b) I have attended most of the AEP classes (7-8 classes); (c) I have attended about half of the classes (5-6 classes); (d) I have attended some classes (3-4 classes); or (e) I have attended few classes or none at all (0-2 classes). See 2009 Survey Instrument (on file with author).

163. See 2010 Survey Instrument (on file with author)

164. G.C. Williams \& E.L. Deci, Internalization of Biopsychosocial Values by Medical Students: A Test of Self-Determination Theory, 70 J. OF PERSONALITY AND SOC. PSYCHOL. 767, 769 (1996).

165. See Learning Climate Questionnaire, supra note 150.

166. Id.

167. See Understanding the Negative Effects, supra note 9, at 888.

168. See 2009 \& 2010 Survey Instruments, supra note 154.

169. See id. 
a five-point Likert Scale response type. ${ }^{170}$ Examples include questions such as: "Agree or Disagree: My law school as a whole (including the Academic Excellence Program) has provided explicit opportunities for students to teach themselves how to learn better (i.e. instruction in "learning styles theory," training in "self-regulated learning," etc.)." "71

\section{B. Survey Results}

This section details the results of the surveys, which research administrators submitted to first-year and second-year students late in the fall semester of 2009 (T1) and 2010 (T2). The section will address how the study measured students' perception of autonomy support and humanizing, explain how it used control questions to segregate responses according to the degree to which students participated in academic support measures, and detail the data according to these factors.

\section{Measuring Students' Perception of Autonomy Support and Humanizing.}

To measure students' perception of autonomy support and humanizing, this study broke the results down into two groups: first-year students and second-year students. For both groups, this study coded the answers to the twenty-one substantive questions by ascribing a score of "one" for a "strongly agree" answer, a "two" for a "somewhat agree" answer, a three for a "neither agree nor disagree," a four for "somewhat disagree," and a five for "strongly disagree." Thus, for instance, on the question asking whether the subject believed the law school provides "choices and options that allow me to govern or regulate my own education," a score indicating that the subject "somewhat agreed" would receive two points. Each individual subject's coded answers to the twenty-one substantive questions were then added to produce a "total autonomy support and humanizing score" ("TAS\&HS"). Because the questions were created such that a "strongly agree" answer indicated the highest level of autonomy support and humanizing, and because that response received a "one" while "strongly disagree" answers (i.e. indicating a low level of autonomy support and humanizing") received a score of "five," a low numerical TAS\&HS indicated strong perceived autonomy support and humanizing. In other words: the lower the subject's score, the more the subject perceived the law school as providing autonomy support and a humanized environment.

170. See id.

171. See id. 


\section{Control Measures Used to Sort by Participation.}

Due to the hypothesis of this study, it is important to consider the relevant lens through which to observe these scores. Specifically, to determine whether students more regularly using academic support resources experience greater autonomy support and humanizing, the results of this study should be expressed comparatively. This means sorting the data on substantive questions, e.g. those regarding autonomy support or humanizing, by controlling for the degree to which individual respondent's participated in the academic support resources.

Accordingly, the study compared subjects' TAS\&HS controlling for the degree to which they participated in the academic support resources. New England has multiple facets of its Academic Excellence Program, and the control measures of this study are based on those facets. In the fall semester, first-year students have access to a weekly, voluntary class called "Academic Excellence." each first-year section, and the class teaches students basic law school skills, legal analysis, and how to prepare for exams. ${ }^{173}$ In the spring of students' first year, students have access to one-to-one academic counseling, focusing on improving students' performance, instilling "self-directed learner" skills, and reinforcing legal analysis skills. ${ }^{174}$ Although all students may participate and the Academic Excellence class continues into the spring semester, the law school specifically invites students who underperformed on midyear exams to take part in the individualized, private academic counseling. Finally, in the fall of students' second year, students within the "Academic Concern" category (e.g. those in the bottom third of their section after their first year) are eligible to enroll in an elective two-credit course called "Legal Analysis." 175 This intensive course, which is coupled with the mandatory Evidence course in that all five of the required papers in the course raise evidentiary issues, focuses on providing extensive individual feedback to each student. ${ }^{176}$ This study used each of these facets of the Academic Excellence Programs as control measures to sort students who frequently and pervasively used the academic support services from those students who did not.

For instance, using first-year students' answers to the control question " $[t]$ o what degree have you participated in the weekly Academic Excellence

172. Academic Excellence Program, NEw ENG. L., http://www.nesl.edu/exceptional/academic excellence.cfm (last visited July 26, 2012).

173. See id.

174. See id.

175. See id.

176. Id. 
class?" the study separated these students' TAS\&HS into five groups: (1) those who attended all or nearly all classes; (2) those who attended most of the classes; (3) those who attended about half of the classes; (4) those who attended a few classes; and (5) those who attended few classes or none at all. Each group's average TAS\&HS was then calculated, keeping in mind that the study hypothesis predicted that the first group's TAS\&HS would be lowest and that the score would increase as students' participation in the program decreased.

As for second-year students, these students had more opportunities to participate in the academic support program. Like the first-year students, they had access to the fall semester Academic Excellence class during their first year in law school. Unlike the first-years, who were only one semester into law school when surveyed, the second-year students also had access to the one-to-one academic counseling in their second semester, and students in the bottom third of their class had access to the for-credit "Legal Analysis" class in their third semester. ${ }^{177}$

Accordingly, this study controlled for each of these facets of the program by posing three control questions in the survey distributed to second-year students. The first question, like the survey of the first-year students, asked about the second-year students' participation in the Academic Excellence class during their first year, and this study used the same sorting categories as described above. TAS\&HS was calculated for each of the five categories and compared to determine whether the average scores increased with participation as predicted by the hypothesis.

The second control question asked students whether they had taken advantage of the bi-weekly one-to-one academic counseling offered to students in the spring of their first year. Like the previous question, responses were sorted by categorizing students either as fully participating, substantially participating, somewhat participating, occasionally participating, or not participating. ${ }^{178}$ TAS\&HS was calculated for each of these five categories and compared to determine whether scores increased with participation as predicted by the hypothesis.

Finally, the third control measure was whether students had enrolled in the for-credit Legal Analysis class, available only to students in the bottom third of the class, in their third semester. This control question simply divided students into categories of those who took the class and those who did not. TAS\&HS was again calculated for both categories and compared

177. See Academic Excellence Program, supra note 172.

178. The question in the survey gave detailed definitions of these categories. 
to determine whether these average scores increased with participation as predicted by the hypothesis.

\section{The Data, Organized by Control Measures.}

This subsection provides the data results in the following order: (a) first-year student TAS\&HS, controlling for participation in the Academic Excellence class; (b) second-year student TAS\&HS, controlling for participation in spring one-to-one academic counseling as first-years; and (c) second-year student TAS\&HS, controlling for participation in the Legal Analysis class as second-years.

a. First-year student TAS\&HS, controlling for participation in the Academic Excellence class.

In the 2009 (T1) administration of the survey, 236 first-year students completed a valid survey. ${ }^{179}$ This table shows the reported participation in the Academic Excellence class:

\begin{tabular}{|l|c|c|}
\hline \begin{tabular}{l} 
Level of Participation \\
\hline $\begin{array}{l}\text { Attended all or nearly all classes } \\
(9-10)\end{array}$
\end{tabular} & 106 & $45 \%$ \\
\hline Attended most classes (7-8) & 61 & $26 \%$ \\
\hline $\begin{array}{l}\text { Attended about half of the classes } \\
(5-6)\end{array}$ & 35 & $15 \%$ \\
\hline Attended a few classes (3-4) & 21 & $9 \%$ \\
\hline $\begin{array}{l}\text { Attended very few classes or none } \\
\text { at all (0-2) }\end{array}$ & 13 & $6 \%$ \\
\hline
\end{tabular}

This "participation level" acts as the control measure by which to determine whether TAS\&HS (i.e. the "total autonomy support and humanizing score") differs based upon participation in academic support measures. The following table shows the TAS\&HS of each participation level; a lower

179. For each group of responses noted in this study, a number of completed surveys were rejected due to various inadequacies. For instance, any survey that contained a student's name or identification number was rejected. Any survey response that included multiple answers for one question was rejected. Also, any survey response that showed that the respondent was simply rotely responding, using the same answer for each question, was rejected. This was determined by means of a standard procedure in survey instruments. One of the questions in the survey was "reversed," meaning that while most of the questions were written in positive language (e.g. "My school gives me opportunities for feedback."), this one question was written in the negative (e.g. "I do not like the way some of my instructors talk to me or the class."). If a student's answer to this question was the same as all the others, it most likely indicated that the student was simply rotely filling out the form. 
score indicates a greater degree of perceived autonomy support and humanizing:

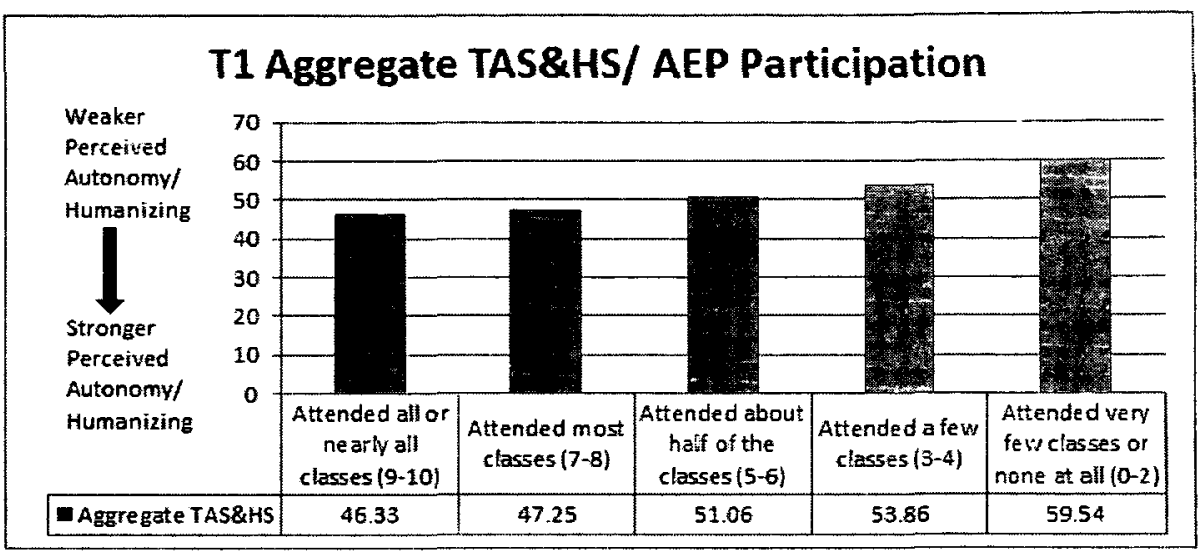

It can be observed that as participation in the academic support increased, so did perceived autonomy support and humanizing. An analysis of variance (ANOVA) test shows that there exists significant difference in TAS\&HS scores among the five groups, with a $P$-value $<0.0001$. The top participants' TAS\&HS (46.33) was $22.18 \%$ stronger than that of the lowest participants (59.54) (keeping in mind that a lower score indicates stronger perceived autonomy support and humanizing). This difference is statistically significant (two-sample t-test $P$-value $<0.0001$ ).

In the 2010 administration of the survey (T2), 252 first-year students completed a valid survey. The following table shows the reported participation in the Academic Excellence class:

\begin{tabular}{|c|c|c|}
\hline Level of Participation & Number & Percenit \\
\hline $\begin{array}{l}\text { Attended all or nearly all classes } \\
(9-10)\end{array}$ & 124 & $49 \%$ \\
\hline Attended most classes (7-8) & 57 & $23 \%$ \\
\hline $\begin{array}{l}\text { Attended about half of the classes } \\
(5-6)\end{array}$ & 32 & $13 \%$ \\
\hline Attended a few classes (3-4) & 20 & $8 \%$ \\
\hline $\begin{array}{l}\text { Attended very few classes or none } \\
\text { at all }(0-2)\end{array}$ & 20 & $8 \%$ \\
\hline
\end{tabular}


Again, this participation rate was used as a control measure, and respondents' TAS\&HS were calculated and sorted by participation to produce the following results:

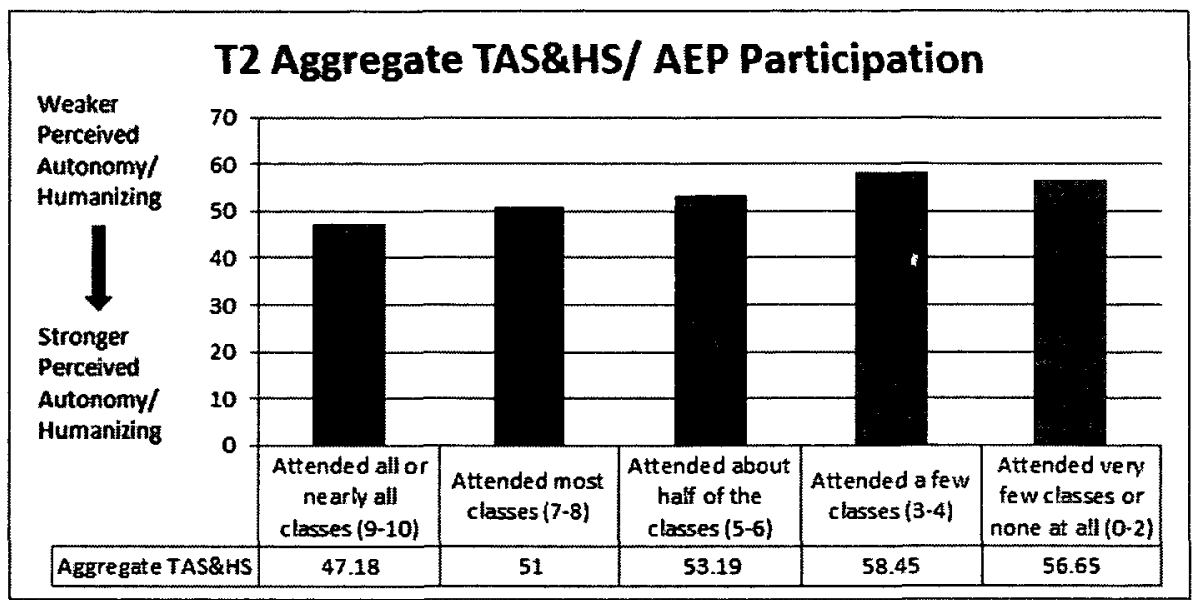

Again, generally speaking, it can be observed that as participation in the academic support measures increased, so did perceived autonomy support and humanizing (ANOVA $P$-value $<0.0001$ ). The one anomaly in this data is that non-participants (0-2 classes attended) had a slightly stronger TAS\&HS compared with the next highest level of participation. Nevertheless, the top participants' TAS\&HS (47.17) was $16.73 \%$ stronger than that of the lowest participants (56.65), once again leading to a statistically significant improvement (t-test $P$-value $<0.0001$ ).

b. Second-year student TAS\&HS, controlling for participation in spring one-to-one academic counseling as first-years.

In the 2009 administration of the survey (T1), 171 second-year students completed a valid survey. The following table shows these students' reported participation in the one-to-one academic counseling, offered in the spring of students' first year: 


\begin{tabular}{|l|c|c|}
\hline Level of Participation & Number & Percent \\
\hline $\begin{array}{l}\text { I met with AEP Faculty regularly and } \\
\text { frequently, and I substantially completed } \\
\text { the study plan work. }\end{array}$ & 13 & $8 \%$ \\
\hline $\begin{array}{l}\text { I met with AEP Faculty regularly and } \\
\text { frequently, but I did not substantially } \\
\text { complete the study plan work. }\end{array}$ & 1 & $1 \%$ \\
\hline I met with AEP Faculty occasionally. & 7 & $4 \%$ \\
\hline I met with AEP Faculty once or twice. & 29 & $17 \%$ \\
\hline I did not meet with AEP Faculty. & 124 & $73 \%$ \\
\hline
\end{tabular}

These participation rates were used as a control measure, and respondents' TAS\&HS were calculated and sorted by participation to produce the results below. Here, though, expressing the results required a different tack. Because the number of respondents within the middle three groups of participation (substantial, occasional, and "once or twice") was so small, these groups were combined to produce a combined TAS\&HS for that whole group. The results were:

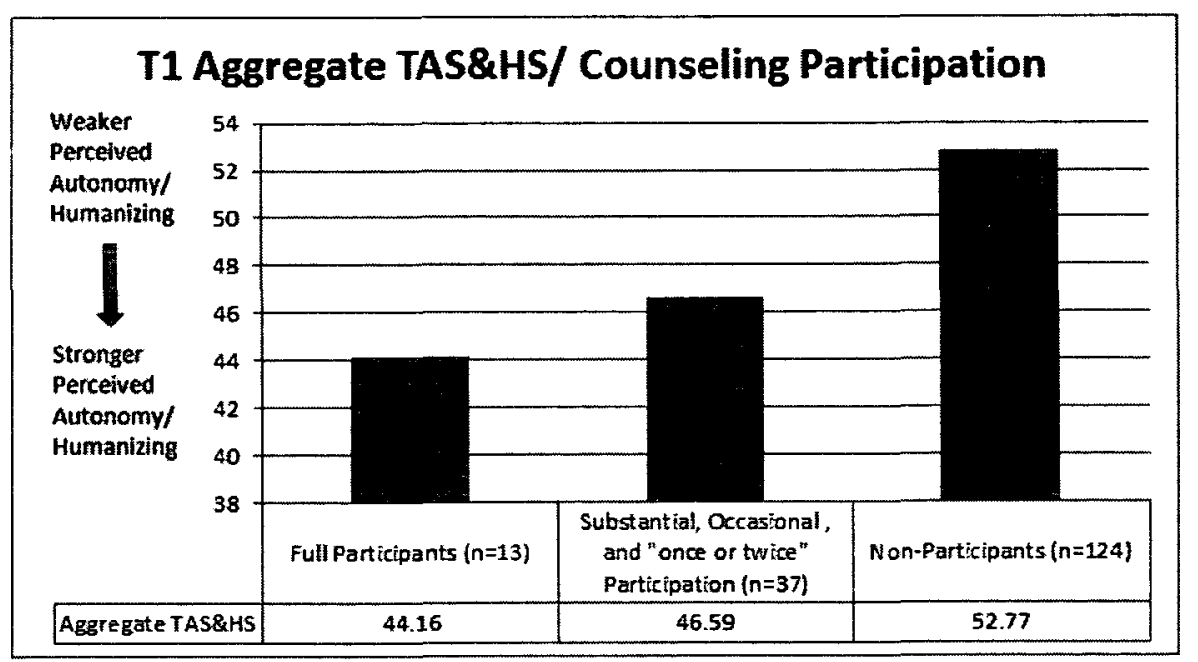

Once again, as participation in the academic counseling increased, so did perceived autonomy support and humanizing (ANOVA $P$ value $=0.0012$ ). Interestingly, there was not a substantial difference in TAS\&HS between the full participants (44.16) and the lesser participants (46.59). The real difference is seen between non-participants (52.77) and 
the others (44.16 and 46.59). The full participants' TAS\&HS (44.16) was $16.32 \%$ stronger than that of the non-participants (52.77), once again leading to a statistically significant improvement (t-test $P$-value $=0.0034)$.

In the 2010 administration of the survey (T2), 188 second year students completed a valid survey. The following table shows these students' reported participation in the one-to-one academic counseling, offered in the spring of students' first year:

\begin{tabular}{|l|c|c|}
\hline \multicolumn{2}{|c|}{ Level of Participation } & Percent \\
\hline $\begin{array}{l}\text { I met with AEP Faculty regularly and } \\
\text { frequently, and I substantially complet- } \\
\text { ed the study plan work. }\end{array}$ & 12 & $6 \%$ \\
\hline $\begin{array}{l}\text { I met with AEP Faculty regularly and } \\
\text { frequently, but I did not substantially } \\
\text { complete the study plan work. }\end{array}$ & 11 & $6 \%$ \\
\hline I met with AEP Faculty occasionally. & 46 & $24 \%$ \\
\hline I met with AEP Faculty once or twice. & 24 & $13 \%$ \\
\hline I did not meet with AEP Faculty. & 95 & $51 \%$ \\
\hline
\end{tabular}

These participation rates were used as a control measure, and respondents' TAS\&HS were calculated and sorted by participation to produce the results below. Unlike the 2009 results, sufficient responses occurred in the middle participation groups to allow statistically significant analyses of the results, and thus combining the groups was unnecessary. The results were:

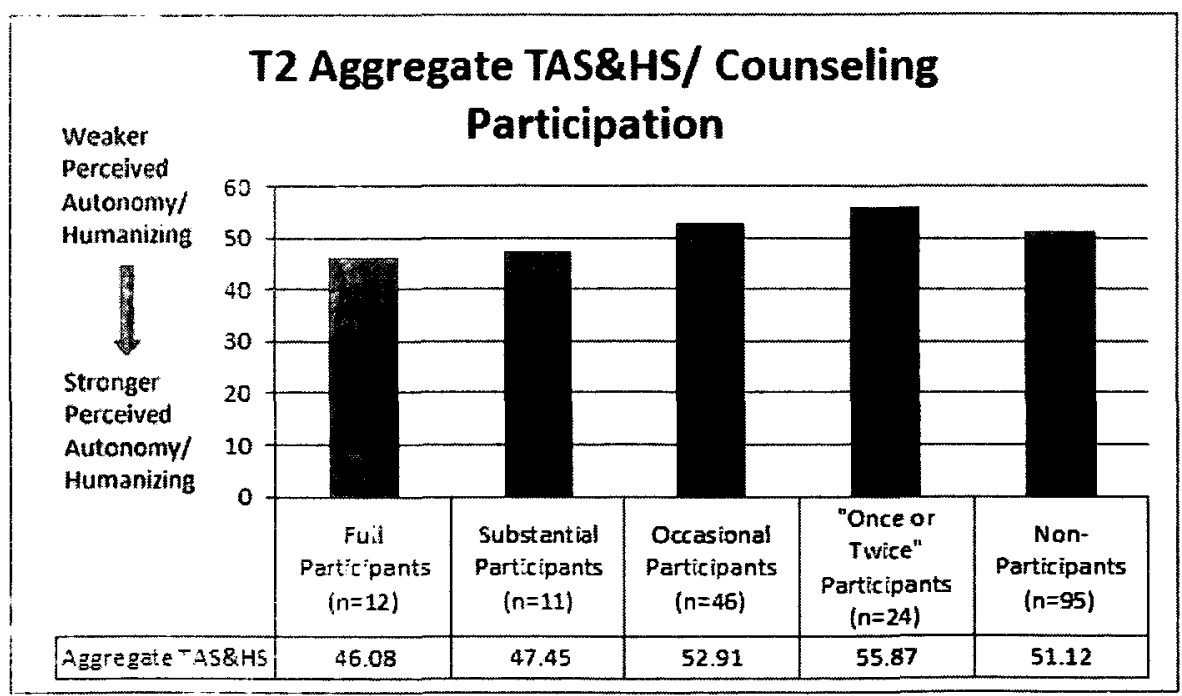


While these results continue to show the tendency for the academic support measures to correlate positively with stronger perceived autonomy support and humanizing (ANOVA $P$-value $=0.043$ ), this data had at least one interesting variant to note. Non-participants report stronger perceived autonomy support and humanizing than the next two higher levels of participation. One hypothesis for this is that if students participated only occasionally or once or twice in the academic counseling, chances are good that they discontinued participation because they found it unhelpful. If that is the case, then those students might just more weakly perceive autonomy support and humanizing than the non-participants who never experienced the negative interaction. Nevertheless, the participants at the higher end of the spectrum, full and substantial participants, reported stronger TAS\&HS (46.08 and 47.45, respectively) than non-participants (51.12). These results were statistically significant (t-test $P$-value $=0.037$ ).

c. Second-year student TAS\&HS, controlling for participation in the Legal Analysis class as second-years.

In the 2009 administration of the survey (T1), 171 second-year students completed a valid survey. The following table shows these students' reported participation in the for-credit, elective "Legal Analysis," class open to students on "Academic Concern":

\begin{tabular}{|l|c|c|}
\hline \multicolumn{1}{|c|}{ Level of Participation } & Number ${ }^{\mathrm{I} 81}$ & Percent \\
\hline $\begin{array}{l}\text { I enrolled in the Legal Analysis } \\
\text { class. }\end{array}$ & 26 & $15 \%$ \\
\hline $\begin{array}{l}\text { I did not enroll in the Legal Analy- } \\
\text { sis class. }\end{array}$ & 145 & $85 \%$ \\
\hline
\end{tabular}

This participation rate was used as a control measure, and respondents' TAS\&HS were calculated and sorted by participation to produce the following results:

180. The number of Legal Analysis students responding, just twenty-six, requires comment. There are three sections of the Legal Analysis course, each capped at twenty. One section is solely for evening students, so those students were not surveyed. Nonetheless, there were forty full-time Legal Analysis students in 2009 , as with every year, so it is somewhat odd that only twenty-six responded. One hypothesis is that such students opted out of the survey to avoid any stigma attached to disclosure of enrollment in the course. The twenty-six responses constitute a response rate of sixty-five percent, which still represents an adequate response rate to deem the results statistically valid. 


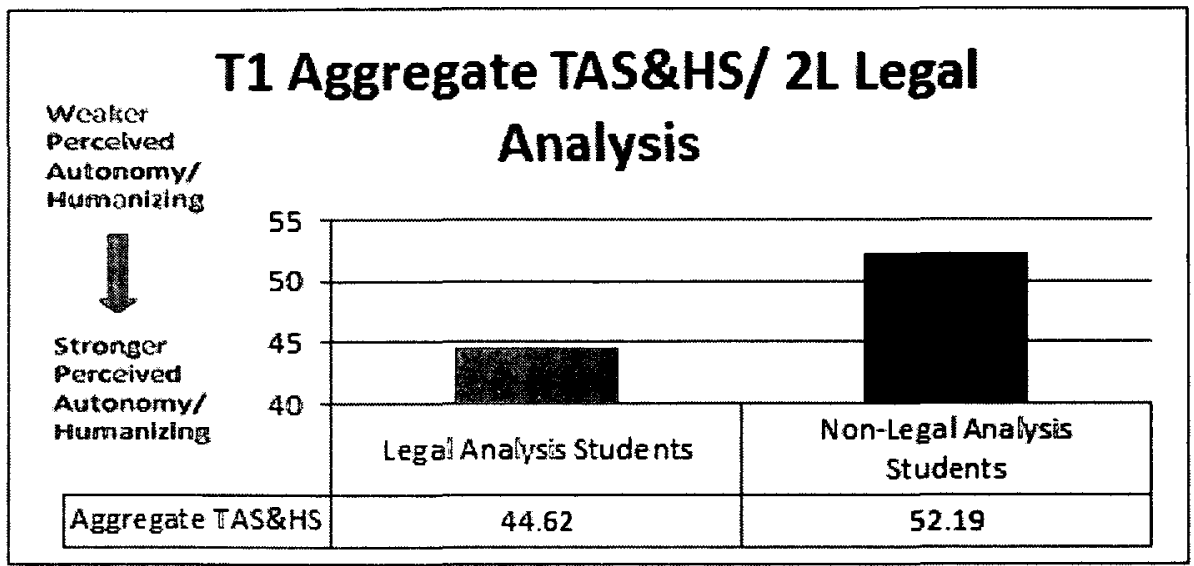

This data shows that enrollment in the Legal Analysis class made it more likely that a student would demonstrate increased perception of autonomy support and humanizing. The TAS\&HS of those enrolling in Legal Analysis (44.62) was $14.5 \%$ stronger than that of the lowest participants (52.19), leading to a statistically significant improvement (t-test $P$-value $=0.0003$ ).

In the 2010 administration of the survey (T2), 188 second-year students completed a valid survey. The following table shows these students' reported participation in the for-credit, elective "Legal Analysis," class open to students on "Academic Concern":

\begin{tabular}{|c|c|c|}
\hline Level of Participation & Number & Percent \\
\hline $\begin{array}{l}\text { I enrolled in the Legal Analysis } \\
\text { class. }\end{array}$ & 31 & $16 \%$ \\
\hline $\begin{array}{l}\text { I did not enroll in the Legal Analysis } \\
\text { class. }\end{array}$ & 157 & $84 \%$ \\
\hline
\end{tabular}

This participation rate was used as a control measure, and respondents' TAS\&HS were calculated and sorted by participation to produce the following results: 


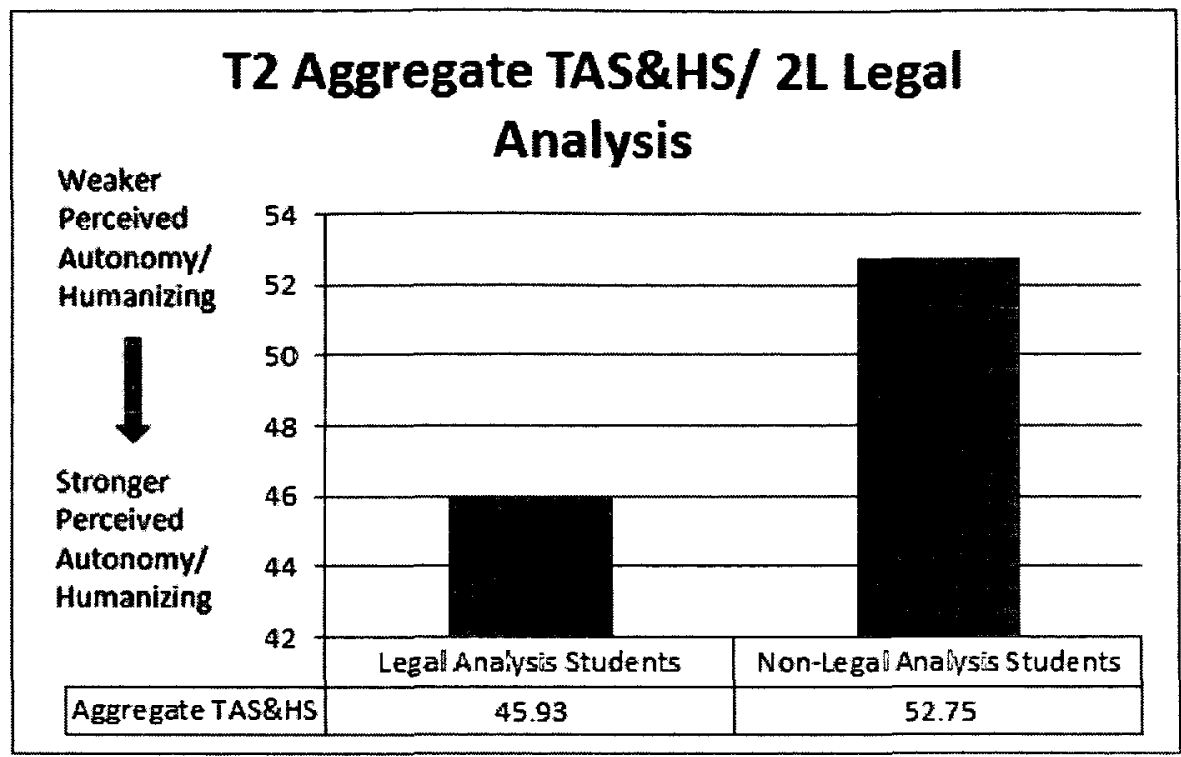

This data shows that enrollment in the Legal Analysis class made it more likely that a student would demonstrate increased perception of autonomy support and humanizing. The TAS\&HS of those enrolling in Legal Analysis (45.93) was $12.93 \%$ stronger than that of the lowest participants (52.75), leading to a statistically significant improvement (t-test $P$-value $=0.0002$ ).

\section{The Data, Organized by Particular Individual Questions.}

Some of the individual questions yield interesting results. This subsection details them.

\section{a. Does Your Law School Support Your Success?}

Question 8 in the second-year survey stated: "Agree or disagree: I believe that my law school has implemented programs or policies whose explicit purpose is to support students' academic success; and I have benefited from these programs or policies." Controlling for whether students enrolled in the Legal Analysis class, the results showed the following for 2009: 


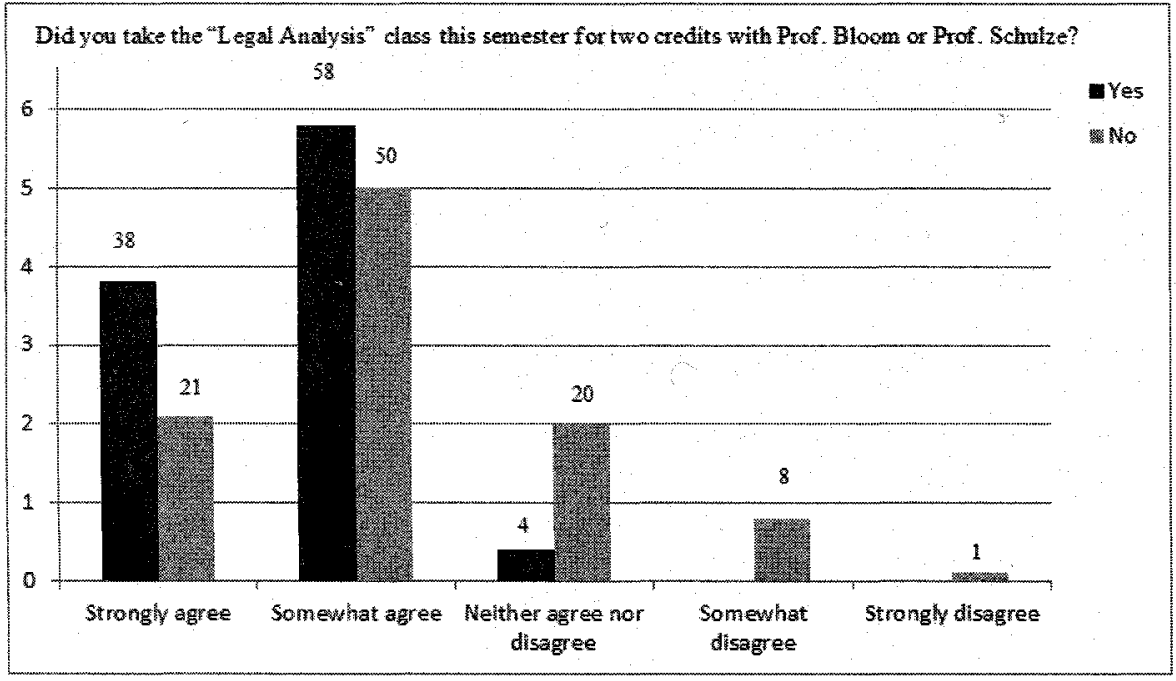

The results for the same question in 2010 showed the following:

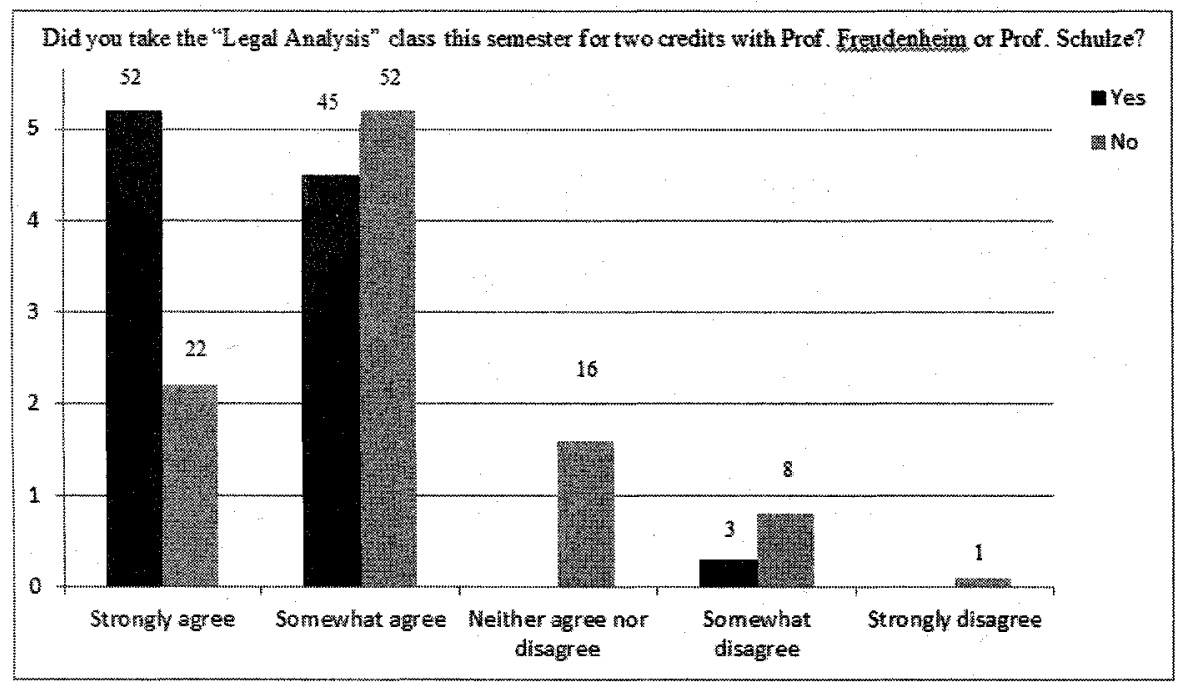

In both years, very few Legal Analysis students (4\% in 2009 and $3 \%$ in 2010) gave an answer other than "strongly agree" or "somewhat agree." The students not enrolled in that course, by contrast, responded neutrally or negatively far more often (29\% in 2009 and $25 \%$ in 2010). Moreover, 
Legal Analysis students were more likely to "Strongly Agree" in both years ( $38 \%$ vs. $21 \%$ in 2009 and $52 \%$ vs. $22 \%$ in 2010 ).

b. Does the Academic Support Program Substantially Contribute to Your Perception of Autonomy Support and Humanizing at the Law School?

The final question of the first year survey posited: "Agree or disagree: My law school's academic support program substantially and positively influenced my answer to questions 4-24." The purpose of this question was to measure whether the Academic Excellence Program had a real impact on students' perception of the law school. Controlling for students' participation in the first-year Academic Excellence classes yielded the following results in 2009:

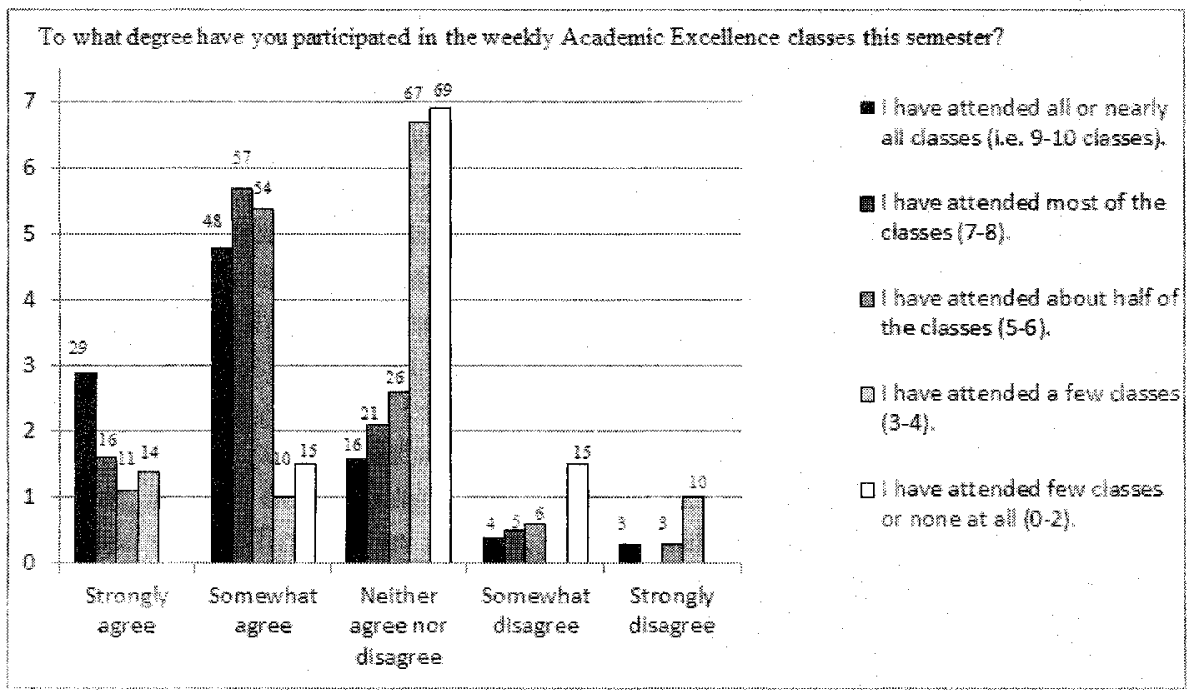


The same question in the 2010 administration, using the same control measure, yielded:

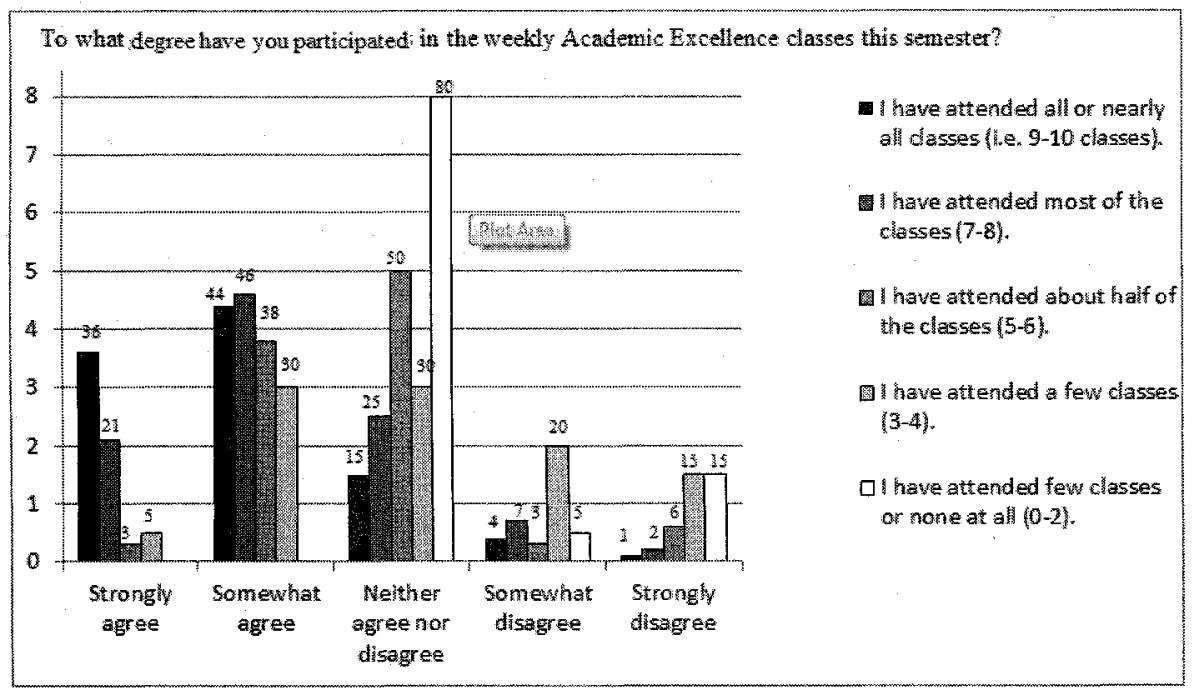

It is fairly apparent from these results that participation in the Academic Excellence class substantially contributed to students' answers to the autonomy support and humanizing questions in the survey. For instance, fully participating students in both years were far more likely to respond positively to the statement $(77 \%$ in 2009 and $80 \%$ in 2010$)$ than nonparticipating students ( $15 \%$ in 2009 and $0 \%$ in 2010$)$.

\section{Analysis}

The data, particularly when coupled with cross-tabulated control measures, sheds light on the impact of the Academic Excellence Program at New England Law. ${ }^{181}$ Moreover, the data gives some indication that certain features of that program were instrumental in leading to the positive correlation with increased perception of autonomy support and humanizing ("PAS\&H").

For instance, the first year Academic Excellence class at New England is weekly and meets at least ten times per semester. This fact appears to be critical to the program's impact on PAS\&H because the aggregate score of

181. Obviously, one weakness of this study is that it tested only one law school. As noted in supra Part IV.A.2., this was due to the fact that schools without ASPs mostly balked at the opportunity to study these issues at their schools. We hope is that the publication of this piece might forge a change in that decision, and we hope that this experiment can be replicated at other law schools with ASPs. 
each participation level increased with each increase in participation. For instance, in 2009 the group who attended nine or ten classes had a TAS\&HS of 46.33, the group who attended seven or eight classes had a TAS\&HS nearly a full point higher (showing weaker PAS\&H), the group who attended 5-6 classes increased nearly another four points, the group attending 3-4 classes increased over two points from there, and the nonparticipating group had a TAS\&HS almost six points higher than the second lowest participation group. ${ }^{182}$ This shows that it is cricial, in terms of supporting autonomy and demonstrating humanization, that ASP classes meet frequently.

Second, it is clear that individual academic counseling is also crucial to supporting autonomy and instilling humanization and that the counseling should be ongoing, frequent, and pervasive. In both years, each participation group's TAS\&HS increases significantly between intervals. For instance, in 2009 full participants in counseling scored a 44.1, while the next group (i.e. the composite group consisting of substantial, occasional, and "once or twice" participants) scored a weaker score by over two points. Moreover, the non-participants added another six points to demonstrate the weakest perception of autonomy support and humanizing of any group. Additionally, the data from 2010, where the lowest three participating groups show no significant improvement in PAS\&H between each other, might suggest that significant improvement in PAS\&H does not occur until the academic counseling occurs at least monthly.

The most striking numbers appear when TAS\&HS is controlled by participation in the second-year Legal Analysis. In both years, students who enrolled in the course demonstrated substantially greater PAS\&H than those who did not enroll in that course. In 2009, the Legal Analysis group scored a 44.62, while the non-Legal Analysis group was almost six points weaker with a 52.19 TAS\&HS. In 2010, similar results occurred: Legal Analysis students scored 45.93, while non-Legal Analysis scored almost seven points weaker with a 52.75. This result is remarkable, given that the Legal Analysis course is open only to second-year students within the "Academic Concern" category, e.g. those in the bottom third of their class after first year. One would think that this group, disheartened after receiving grades placing them in the bottom of the class, would believe that their law school has failed to support them and has failed to become "humanized."183 Instead, these students' scores demonstrate that they are in a more psychologically healthy state, at least with respect to PAS\&H, than students

182. See supra, Part IV.B.3.a.

183. See CARNEGIE REPORT, supra note 5, at 165. 
with higher grades. The power and value of such a course cannot be overstated, and it is extraordinary that some law schools refuse to empower their academic support programs with for-credit and graded courses that would provide hope and assistance to many struggling students.

\section{CONCLUSION}

The original purpose of this series of papers, each sequentially entitled "Alternative Justifications for Law School Academic Support Programs," was to articulate the reasons why ASPs benefit students and law schools in ways other than directly impacting struggling students' grades or likelihood of bar passage. In the first episode of the series, the author explored how certain ASP methods at various law schools enhanced autonomy support and humanized the law school. In the second installment, the author explained how "academic support across the curriculum" helps law schools meet the call for reform in legal education as heralded by the Carnegie Report and the Best Practices text. In the instant piece, we attempted to prove empirically that ASPs foster an increased perceived autonomy support and likelihood of recognizing one's law school as "humanized."

So, what is the point? Assuming that these results are empirically solid and generalizable, and we have made every effort to ensure that they are, what message can we take away from this evidence that ASPs enhance autonomy support and assist in humanizing? One of the possible conclusions actually goes beyond the scope of this series of articles: e.g. the presumption that we would not address how ASPs directly impact students GPAs and bar passage rates. For, if ASPs do actually improve autonomy support, education psychology experts tell us that this would tend to impact students' performance positively. ${ }^{184}$ Therefore, for those interested in proving that ASPs actually render statistically observable improvements in participating students, the instant study may help in that mission.

But is that all that we should care about? Should the sole role of ASPs be to improve the output measures of the small group of students to whom academic support services currently are delivered? Or, should we be looking at a bigger picture? If ASPs have the power to make students perceive that their law schools actually support their autonomy to be involved in their own learning, and if ASPs also help law schools provide a more humane, psychologically beneficial (or at least benign) environment, should that not be a goal in and of itself, irrespective of whether ASPs increase GPAs and bar passage rates? For, that is the second conclusion that we can draw from this study: that academic support methods are

184. See Understanding the Negative Effects, supra note 9. 
important as a means by which to promote autonomy support and law school humanization, irrespective of whether that impact leads to demonstrable improvements in performance.

We suggest that if a law school wants to put its money where its mouth is, and it does indeed care not only about GPAs and bar passage rates but also about its students' psychological well-being, both conclusions we might draw from this study are relevant and important. If academic support measures increase students' performance and promote autonomy support and humanize the law school experience, why then are ASPs the exception and not the rule? Why do some law schools strenuously boast of extensive ASP services on their websites but then commit only meager resources in reality? And why are ASPs often segregated in the academy away from any meaningful integration within the mainstream curriculum? We suggest that the results of the instant study, coupled with information from educational psychology and studies of legal education reform, demonstrate that a law school's commitment to pervasive, effective, and integrated "academic support across the curriculum" is most certainly worth the investment. 
. 